Publicado por primera vez en:

Toro, Alfonso de. (2004). "Reflexiones sobre fundamentos de investigación transdisciplinaria, transcultural y transtextual en las ciencias del teatro en el contexto de una teoría postmoderna y postcolonial de la 'hibridez' e 'inter'medialidad", in: Alfonso de Toro (Ed.). Estrategias postmodernas y postcoloniales en el teatro latinoamericano actual. Hibridez - Medialidad Cuerpo. (Theorie und Praxis des Theaters, Vol. 11, Frankfurt am Main: Vervuert). p. 105-159. 


\author{
Alfonso de Toro \\ Ibero-Amerikanisches Forschungsseminar \\ Universität Leipzig
}

\title{
REFLEXIONES SOBRE FUNDAMENTOS DE INVESTIGACIÓN TRANSDISCIPLINARIA, TRANSCULTURAL Y TRANSTEXTUAL EN LAS CIENCIAS DEL TEATRO EN EL CONTEXTO DE UNA TEORÍA POSTMODERNA Y POSTCOLONIAL DE LA 'HIBRIDEZ' E 'INTER-MEDIALIDAD'
}

\section{REFLEXIONES PRELIMINARES}

Desde la fundación de los primeros institutos de ciencias teatrales en Alemania en el primer tercio del siglo XX y de la introducción de esta disciplina como carrera universitaria en Colonia en 1938 y en Berlín en 1943, así como desde la creación de un número considerable de institutos y cátedras de ciencias del teatro en los años $70 \mathrm{y}$ la inauguración de un amplio y profundo debate teórico en este campo, no se logró establecer un lazo y un contexto de trabajo mutuo entre las ciencias teatrales y las literarias. Mientras la ciencia teatral -luego de una primera época empírica e historicistafundamentó su análisis principalmente en el hecho escénico y, con el tiempo, fue incluyendo en forma más intensa diversos aspectos culturales, antropológicos, históricos y sociales ${ }^{1}$; la ciencia literaria y las diversas filologías, por el contrario, se concentraron especialmente en el análisis del texto dramático, analizando el teatro como un objeto literario. Así, ambas disciplinas permanecen hasta la fecha divididas y sin conexión mayor a pesar de tener un objeto en común y de basarse, desde los años 70 , en teorías similares como el estructuralismo y la semiótica.

* Este trabajo se orienta básicamente en dos conferencias. La primera, con el título "Reflexiones sobre fundamentos de investigación transdisciplinaria en las ciencias del teatro en el contexto de una teoría postmoderna y postcolonial", fue dictada en Stuttgart en el "III. Internationales Symposium zum modernen Theater Lateinamerikas", llevado a cabo del 11 al 13 de junio de 1998, y hasta la fecha no ha sido publicada; la segunda conferencia, también inédita, "Differentielle Anthropologie. Interkulturelles Verstehen", fue presentada dentro de un proyecto científico titulado "Differentielle Anthropologie und postkoloniale Theorie. Die Konstruktion des 'Wir' und des 'Anderen': Das Aushandeln der Andersheit', realizado en Großbothen/Leipzig del 24 al 25 de julio de 1999.

1 Para un panorama del desarrollo de las ciencias del teatro en Alemania desde su fundación como disciplina universitaria, vid. Möhrmann (1990: 7-20), Girshausen (1990) y FischerLichte (1994). 
Aunque la ciencia literaria (como también la lingüística) poseía una sólida base científica y modelos analíticos, esto no fue el caso en la ciencia teatral sino hasta comienzos de los años 70. Estos modelos se introdujeron cuando el empirismo histórico y el inmanentismo analítico del espectáculo -considerados como los únicos métodos para el trato del objeto teatral- fueron desplazados y superados. Posiblemente la razón de este retrazo teórico en la ciencia teatral radique en el objeto mismo de su análisis. En todo caso, el hecho es que un diálogo entre la ciencia del teatro con otras disciplinas tales como la teoría literaria y de la cultura no tuvo lugar.

Es fácil constatar que la ciencia del teatro solamente con un gran esfuerzo y bastante tarde obtuvo el instrumentario científico con sólidos modelos de interpretación que pudiesen competir y ser comparados con otras disciplinas humanísticas. El predominio teórico yacía en la ciencia literaria desde los años 20, y los modelos que caducaban se reemplazaban con enorme velocidad. En los años 60, la ciencia del teatro carecía de personalidades como Barthes, Lévi-Strauss, Brémond, Todorov, entre muchísimas otras, cuyos trabajos, y la influencia de Derrida, Lacan y Foucault facilitaron, a comienzos de los años 70, la aparición de teorías como la de Jauß (Ästhetische Erfahrung), la del grupo Tel Quel y la de Roland Barthes (S/Z y Plaisir du texte), iniciando, así, un cambio de paradigma con respecto al concepto de ciencia y de interpretación y posibilitando además la teoría de la cultura de Said, Bhabha o Spivak.

Todavía en los años 70 y 80 -por muy diversas razones y muchas veces completamente opuestas- se consideraba el estado de la construcción teórica dentro de la ciencia teatral como insatisfactorio. Así, Steinbeck (1970) lamentaba la falta de "una terminología exclusiva para el teatro" ("reine theatralische Terminologie") y Feiler (1974: 7-8) comparaba el teatro con un paciente que sufría a raíz del caos terminológico de sus médicos. Hay una gran cantidad de trabajos que se comportan indiferentes a la estructura propiamente teatral y Eco (1977) declara que lo mejor que la ciencia teatral había hecho era introducir la semiótica de la teoría literaria y de la cultura.

Esta situación ha cambiado tanto en el nivel nacional como en el internacional, particularmente en Alemania donde el cambio de algunos aspectos fundamentales en los últimos veinticinco años ha sido radical, por ejemplo, en el nivel metodológico e institucional. Fuera de la creación de numerosos institutos de ciencia del teatro se introduce el estructuralismo, la semiótica, la semiótica de la cultura y la teoría de la recepción (vid. Helbo 1975; Kowzan 1975; van Kesteren 1975; Pfister 1977; Pavis 1976, 1982; Ubersfeld 1977; Elam 1980; De Marinis 1982; Fischer-Lichte 1983; F. de Toro 1987 ó 1995). Más tarde, a partir de la segunda mitad de los años 80, especialmente en los 90 y como consecuencia de lo ocurrido en la ciencia literaria a fines de los 70, se comienza a trabajar en la ciencia del teatro con la teoría de la cultura y con los Cultural Studies, con conceptos del postestructuralismo, de la filosofía postmoderna y de la historia, ampliando de esta forma considerablemente su horizonte 
teórico y metodológico. Esta ampliación transdisciplinaria es de tal envergadura que se le puede considerar sin precedentes ${ }^{2}$.

Frente a este panorama es sorprendente que ambas disciplinas, a pesar de compartir las mismas bases teóricas y metodológicas, no hayan conseguido establecer un diálogo. No obstante esta situación existe seguramente consenso sobre el hecho de que nuestros objetos culturales pueden ser tratados adecuadamente dentro de un marco transdisciplinario y transcultural.

En el contexto de una semejante aproximación teórica, entendemos el objeto "teatro" como una unidad semiótico-cultural y epistemológica dentro del concepto de ciencia en un mundo globalizado e internacionalizado con la evidente posibilidad de superar provincialismos y esencialismos, sin que esto signifique el descartar aspectos centrales de la diferencia cultural. Se trata más bien de una focalización e internacionalización de ciertos campos y bases de investigación y reflexión comunes; exactamente en este contexto se ubica el presente trabajo.

Una aproximación teórica y metodológica transdisciplinaria de la ciencia del teatro y de la literaria es una tardía respuesta al desarrollo velocísimo de las formas de la representación cultural y del teatro actual, permitiendo a la vez una relectura y una nueva interpretación del teatro de siglos anteriores.

El teatro actual exige una amplia y flexible respuesta de parte de la ciencia teatral para evitar aquello que Eduardo Pavlovsky reclama a comienzo de los años 90:

[...] por una parte existe una cierta cantidad de críticos que no están al tanto de lo que sucede hoy en el mundo y no poseen los instrumentos analíticos para tratar el teatro y por otra los críticos informados han sido avasallados por la rapidez y variedad del teatro actual: necesitamos nuevos críticos jóvenes que acompañen estas vanguardias. (Carta de E. Pavlovsky al autor del trabajo)

Mientras hoy en día la ciencia del teatro en Europa y Norteamérica representa una de las disciplinas más avanzadas y fascinantes con respecto a las innovaciones teóricas, la ocupación científica del teatro en Latinoamérica permanece insatisfactoria, ya que aún $-\mathrm{y}$ a pesar de notables esfuerzos- sólo se practica marginalmente en el medio académico. Este estado no es comparable al desarrollo del teatro latinoamericano desde los años 80 que no resulta menos interesante y novedoso que lo que ocurre en otras partes del mundo. Por una parte casi no existen las "cátedras de teatro" ni los

2 Por ejemplo, los proyectos dirigido por Fischer-Lichte con los temas "Theatralität und die Krise der Repräsentation", "Das Eigene und das Fremde" y "Körperinszenierung"; "Übergänge und Spannungsfelder zwischen Mündlichkeit und Schriftlichkeit" e "Identität und Alterität" ("Teatralidad y crisis de la representación", "Lo propio y lo ajeno", "Escenificación corporal", "Transición y campos de tensión entre la oralidad y la escritura" e "Identidad y alteridad"). Semejantes proyectos se registran también en la ciencia literaria, por ejemplo en Friburgo con los temas "Übergänge und Spannungsfelder zwischen Mündlichkeit und Schriftlichkeit" (1995/96) o "Identität und Alterität" (desde 1997) o nuestro proyecto "Pluralidad de discursos..." (1997 - 2001) en Leipzig. 
"institutos de teatro" concebidos como escuelas dedicadas a la investigación científica del mismo, aun cuando en diversas universidades e instituciones se hayan creado "unidades de investigación teatral" con revistas especializadas y colecciones científicas. Por otro lado, las escuelas o institutos de teatro fungen en primer lugar como escuelas de entrenamiento actoral y de dirección teatral, en las que al final de los estudios se les imparten a los estudiantes materias académicas del teatro. El trabajo propiamente científico se desarrolla principalmente a nivel individual (personal) dentro y fuera de la academia a través de personas que dedican parte de su trabajo a la investigación científica del teatro. Semejante organización en la enseñanza e investigación tiene naturalmente consecuencias en la sustancia de los resultados obtenidos.

Sin embargo, también en el sistema universitario alemán tenemos -respecto de la investigación del teatro latinoamericano- una situación altamente precaria: éste no tiene un lugar determinado ni en la enseñanza ni en la investigación; es particularmente marginal. Las razones son de diversa índole; una de ellas radica quizás en el hecho de que la "latinoamericanística" como carrera - con sus respectivas cátedrasaún no está ampliamente establecida, exceptuando obviamente aquellos casos en los que los catedráticos tienen una dedicación prácticamente exclusiva al campo. Además, el término 'latinoamericanística' solapa el hecho de que se trata de una carrera que cubre un enorme continente con diversas culturas que no puede ser abarcado en su totalidad simultáneamente ni ser estudiado en la forma debida, aún dentro de las cátedras especializadas. Así, el trabajo en la 'latinoamericanística' se convierte en una especie de isla de interés personal que se especializa particularmente en la teoría de la cultura y en la literatura ${ }^{3}$.

La ocupación con el teatro latinoamericano actual permanece marginal en el panorama universitario alemán -como indica Floeck (1993)-, quizás debido al difícil acceso a las obras y, en parte también, a la investigación realizada en Latinoamérica o a la falta de la experiencia directa de la representación teatral. Pese a la creación de colecciones dedicadas a la publicación de trabajos científicos sobre el teatro latinoamericano tales como Theorie und Praxis des Theaters (TPT) o Theater in Lateinamerika (ambas en la editorial Vervuert de Francfort) y a pesar de que se hayan fundado instituciones que se ocupen de la traducción y difusión de dramaturgos latinaomericanos y de que desde 1989 se hayan realizado varios congresos y coloquios relativos al tema, la situación a nivel universitario no ha cambiado notoriamente.

Asimismo insistimos en que la ausencia del teatro latinoamericano o su gran marginalidad en Alemania se presenta también en los Institutos de Ciencia del Teatro

3 Otra razón básica es que la "latinoamericanística', como la "hispanística" o la "italianística", forman parte de los "estudios de romanística" que corresponden a la estructura tanto de la educación como de la enseñanza y la investigación. 
dentro de la ciencia teatral tanto en el nivel institucional como en los de enseñanza e investigación. En el nivel general de la investigación constatamos su inexistencia, incluso en publicaciones que se ocupan, dentro del contexto del teatro, de problemas tales como la 'traducción', la 'diferencia', 'lo propio'/'lo extraño'/‘el otro', o también de la 'interculturalidad y multiculturalidad', el 'cross cultural' y de fenómenos de hibridización -por ejemplo las relaciones entre el teatro europeo y el oriental, el asiático o el africano. Se investigan campos de investigación que pertenecen ya al repertorio clásico como lo son Artaud, Le Théâtre du soleil, Odyn Theatret por una parte y el kabuki y el teatro $n$ « por otra, pero que no mencionan al teatro latinoamericano. El volumen The Dramatic Touch of Difference. Theatre, Own and Foreign (Fischer-Lichte/Riley/Gissenwehrer 1990) representa un buen ejemplo de lo anterior: se ocupa del teatro europeo, norteamericano, japonés, indonesio, indio y africano pero se olvida del latinoamericano; es inexistente a pesar de que el teatro latinoamericano constituye un campo privilegiado para semejante estudio, ya que desde sus comienzos ha sido híbrido. ${ }^{4}$ Como Balme (1995: 2) indica en su trabajo, la ciencia teatral alemana (y no sólo ésta) opera de una forma altamente "eurocentrista": se analizan expresiones teatrales asiáticas o africanas, especialmente si éstas han entrado de alguna forma en el sistema cultural europeo.

Al respecto, las contribuciones de Villegas (p.e. 1988), han sido pioneras en el campo de la investigación teatral, en cuanto han mostrado cómo Europa ha construido y excluido al teatro latinoamericano según sus conveniencias y parámetros y cómo mecanismos hegemónicos operan en las ciencias de la cultura.

Considerando una serie de trabajos propios sobre la teoría de la cultura y de la literatura, como también un buen número de publicaciones de corte transdisciplinario y teórico-cultural dentro y fuera de la disciplina del teatro, la finalidad primordial en este trabajo consiste en dar respuesta a la pregunta de cómo el objeto 'teatro' puede ser visto, leído, descrito e interpretado, de tal forma que éste pueda ser analizado de una forma científica amplia y adecuada, al par con nuestro tiempo. Constantemente indicaremos en qué publicaciones y en qué sectores se han hecho notables y decisivos avances y en dónde existen carencias para así posicionarnos científicamente.

4 En relación con el teatro latinoamericano se puede constatar algo similar a lo acontecido con el teatro español del Siglo de Oro y lo que en parte aún sucede con el teatro español contemporáneo: exceptuando la mención de La Vida es sueño o El Príncipe Constante de Calderón, es un esfuerzo vano buscar estudios en monografías generales sobre la tragedia, la comedia $o$ la tragicomedia clásica europea o sobre el teatro español y latinoamericano actual. En el mejor de los casos se les concede una nota a pie de página. Podemos incluso sostener que el teatro latinoamericano en el medio académico (y no sólo en éste) es inexistente, tanto en Alemania como en Europa en publicaciones generales sobre el teatro contemporáneo, lo cual parece incomprensible si se considera que a más tardar desde 1989, en Alemania, es posible obtener trabajos sobre "interculturalidad" en Alemania provenientes del extranjero o sobre otros aspectos del teatro latinoamericano. 
La dirección de investigación que propondré trasciende la perspectiva de la exclusividad de una disciplina en particular o de una región, ya que un procedimiento exclusivista no solamente repetiría el canon imperante, sino que además nos llevaría a una reducción o generalización de posibilidades interpretativas. Favorecemos nuestro aproximamiento por la simple razón de que tanto la ciencia como la cultura à la longue no se pueden limitar con lazos ideológicos o regionales. Además, los complejos problemas que representa no tan sólo el objeto 'teatro', sino también sus actantes, el dramaturgo, el director y los actores, exigen y reclaman un amplio contexto argumentativo.

Los instrumentos elegidos arrancan del objeto 'teatro' mismo y del lugar epistemológico desde donde parte mi argumentación. Mi perspectiva está relacionada con la discusión sobre actuales problemas en la ciencia teatral, su metodología y sus teorías y no con asuntos de carácter local, aunque aspectos teórico-culturales se inscriben en los diversos objetos. Muchas veces, por razones de una gran delimitación del campo de investigación, el teatro latinoamericano ha quedado, por ejemplo, fuera de la discusión actual.

\subsection{Ciencia del teatro y teoría de la cultura como un concepto científico trans- relacional y transversal}

Mi aproximación transdisciplinaria parte de dos conceptos o estrategias: de la 'hibridez'/'hibridización' y de la 'transmedialidad'. Ambas unidades no son solamente parte inherente del teatro, sino también de la actual discusión en la ciencia teatral (cfr. bibliografía). Además constatamos que se ha producido un constante proceso de hibridización de carácter global, en el cual nos encontramos, y que sin embargo ha sido a la vez muy diferenciado, tanto en el teatro como también en la cultura y en la sociedad en general.

Una concepción de orientación 'transdisciplinaria' en el contexto de una amplia semiótica de la cultura y de la teoría de la cultura es imprescindible porque problemas de hibridización y transmedialidad, lo mismo que su marco discursivo, solamente pueden ser tratados en forma adecuada si se superan los límites de países, autores y disciplinas. Esta perspectiva contribuye así a colocar al teatro en general en un amplio contexto epistemológico y a liberar, por ejemplo, al teatro latinoamericano de lo 'exótico' y de lo 'mimético-reproductivo'; esto es, liberarlo de una mirada e interpretación hegemónica (eurocentrista) -aún fuertemente existente-, y permitir discutirlo en un contexto internacional como un teatro de una rica e innovativa tradición, como lo han practicado Todorov $(1982,1989)$ dentro de la teoría de la cultura francesa, Fiebach $(1986,1996,1998)$ con respecto al teatro africano y Balme (1995) en relación con el teatro anglófono. 
Una aproximación transdisciplinaria tiene como finalidad la superación de los límites de la propia disciplina y emplear otras disciplinas tales como las ciencias históricas, de la cultura, de los medios de comunicación, la filosofía o sociología como ciencias auxiliares para así confrontarse con la manifestación cultural 'teatro' de tal forma que pueda dar respuesta a lo que está sucediendo hoy en el teatro, y permita entrelazar recíprocamente tanto el objeto de investigación como la teoría. Además, la aproximación transcultural contribuye a superar, o al menos a reflexionar barreras culturales y con esto prejucios eurocentristas que hoy en día se manifiestan en forma sutil y más velada.

Esta aproximación requiere la conexión y reorganización de diversas disciplinas, de diversas teorías y prácticas en el trato de objetos culturales en un mundo globalizado, lo que atañe en forma muy particular al objeto 'teatro' debido a su carácter público, ritual y gestual. A raíz del estatus híbrido del teatro, sus elementos constituyentes tales como 'texto', 'autor', 'director' y 'actor' deben ser revisados.

Los criterios de hibridez y transmedialidad fomentan un análisis e interpretación transdisciplinaria, transcultural y transtextual, por ejemplo, el diálogo entre diversos códigos culturales y estéticos del teatro latinoamericano, europeo, norteamericano, afroamericano, africano o asiático. Allí radica la necesidad de aclarar los términos hibridez y transmedialidad y su correlación con el teatro. El término hibridez se ha definido en la teoría de la cultura tanto intencional como extensionalmente en forma diversa y, a pesar de una gran bibliografía y de aquella obra de gran influencia de García Canclini (Culturas híbridas 1990/1992/ ${ }^{2} 1995$ ), no existe hasta la fecha una teoría sistemática o un modelo coherente para tratar el fenómeno de la hibridez. Una gran cantidad de obras se agota en meras descripciones generales y eclécticas de algunos procesos culturales híbridos, quedándose así en la superficie y mostrando lo evidente.

El especial trato que le damos al diálogo transtextual y transcultural abre la posibilidad de un amplio contexto de argumentación y reflexión para la interpretación del teatro en general y para la consideración de diferencias culturales en particular, como también para determinar la función de ciertos discursos (p.e. aquellos postmodernos/postcoloniales, sobre poder, sexualidad, cuerpo, deseo, identidad, géneros, deconstrucción, nomadismo, teatralidad, etc.).

Los términos 'función', 'transformación' y 'translación' ('traducción') son parte central de cualquier investigación que esté relacionada con procesos culturales porque no implican solamente momentos sincrónicos, sino al mismo tiempo diacrónicos que se condensan en puntos de entrelazamientos y cruces, concretizándose en el artefacto teatral y adquiriendo una sólida representación social y estética. El momento diacrónico se debe considerar no como una linearidad de eslabones de acciones causales, sino como una descentración temporal; lo cual García Canclini (1990/1992/21995: 15, 72 passim) define como "heterogeneidad multitemporal".

Esta aproximación transdisciplinaria radica, en nuestro caso, en obras provenientes del campo de la filosofía y de la sociología, de autores tales como Derrida, Foucault, Deleuze, Lyotard, Guattari, Baudrillard, Lévinas; de la nueva historiografía 
y de la filosofía de la historia con obras de Le Goff y White o de la teoría de la cultura, representada por Said, Bhabha, Spivak, Ashcroft et alii, Jameson, Coehlo Neto, García Canclini, Bosi, Brunner, Kraniauskas, Martín Barbero, Carlos Rincón, Melo e Souza, Ortiz, Reis, Sodré, Mignolo et alii, Monsiváis, Fanon, Todorov, entre otros. En el campo de la ciencia teatral contamos con los trabajos de Fiebach, Fischer-Lichte, F. de Toro, Villegas, entre muchos otros (vid. bibliografía).

La pluralidad de nuestra aproximación postmoderna/postcolonial diverge sustancialmente de aquella del "pluralismo de método" de los años 60 y 70 , ya que en ella la pluralidad consistía a lo sumo en métodos que no dialogaban el uno con el otro, sino que se excluían mutuamente (estructuralismo vs. hermenéutica vs. teorías marxistas vs. teorías psiconalíticas). En nuestro caso se trata de métodos empleados de forma interrelacional e interracional, como lo demuestra Welsch (1997) basándose en el término de "razón transversal". Esta estrategia de la transversalidad racional nos permite desempeñar una 'ciencia/interpretación transversal' -como quisiera denominar esta forma de aproximación- en diversos contextos. Se trata de una búsqueda, de un entrelazamiento de diversas líneas en puntos de superposición y cruces. Se trata, al fin, de un modus operandi que posibilita relaciones transversales entre diversos sistemas.

Este tipo de ciencia o interpretación transversal no significa de ningún modo "el fin de la ciencia" o de la racionalidad, sino muy por el contrario, se encuentra en el centro de la ciencia; no es "antirracional", sino "interracional", no es arbitrario, sino que está comprometido con la plurivalencia y refleja nuestra época no como Hybris, sino como 'hibridez', debido a que no está suspeditado a ninguna nacionalidad u ontología. No es arché ni está subyugado a un concepto a priori de ciencia, es parte de una Post-Teoría (F. de Toro 1999d).

\subsection{Descentración del Logos y construcción de formas discursivas}

El concepto científico que venimos describiendo es un resultado del pensamiento postmoderno que a su vez se deriva de la disolución del Logos expuesta en las obras de Lacan, Derrida y Foucault, pasando por Deleuze y Baudrillard, y que lleva a un profundo cuestionamiento de los metadiscursos autoritarios y legitimistas.

Hemos explicado este tipo de pensamiento postmoderno basándonos en tres términos o estrategias fundamentales: la memoria (Erinnerung), la elaboración (Verarbeitung) y la perlaboración (Verwindung) (cfr. A. de Toro 1993/1995). El momento de la perlaboración es el más importante porque en él el material canónico se repliega (rückgefaltet/reploiement), injerta (aufgepfropft/greffer) y no se elimina/supera, sino que se perlabora en otra unidad cultural. Los puntos de origen y de llegada de las unidades culturales se mezclan y dejan una huella palimpsesta que se despliega a través de re-marcaciones. Los repliges e injertos no constituyen una síntesis ni una superación (Aufhebung, Überwindung) o represión (Verdrängung). La huella de la diferencia describe la claudicación del logos metafísico occidental, y con esto del 
dualismo, favoreciendo tanto la diferancia (Derrida), la altaridad (Taylor 1987) como también un pensamiento nómada y transversal en el cual categorías binarias excluyentes tales como 'periferia vs. centro' o 'masculino vs. femenino' ya no tienen legitimación o son fuertemente cuestionadas. Las fronteras se permeabilizan para el Marginado, para las Orillas y para la Otredad en general.

El concepto de palimpsesto ya mencionado conecta discursos de diversa naturaleza y de diversas culturas en una tensión no binarista, en una tensión de "negociación" constante de la Otredad. En este contexto se desarrolla la postcolonialidad como estrategia cultural (sin desideologizarla y despolitizarla) que recodifica, perlabora el pasado y el presente en un futuro sin producir un neocolonialismo, ya que este último sería un colonialismo a un nivel más refinado, donde la posibilidad del diálogo se daría solamente desde la perspectiva del centro. De esta forma ni la raza, ni el lugar, ni la importancia geopolítico-tecnológico-científica tendrían una función única y especial en la batalla de los discursos. Se trata de un concepto cultural en un sentido operacional que resulta de una necesidad científica que consiste en delimitar el campo en el cual el científico es competente. Si no diferenciamos entre la producción cultural por una parte, y la producción tecnológico-científica por otra, no solamente caeremos en simplificaciones, sino que le quitaremos la posibilidad de discurso a los países que la tienen, pero que no son potencias económicas y científicas. El término postcolonialidad como categoría cultural naturalmente incluye, dentro de una teoría de la cultura, lo sociológico, lo político, lo económico y lo científico, sin caer en clasificaciones dogmáticas, y considera las contradicciones y discontinuidades ("impurezas") que se dan dentro de los diversos campos de la historia de la cultura. La postcolonialidad como perspectiva postmoderna se caracteriza por una actitud y por un pensamiento deconstruccionista (en el sentido de una reflexión crítico-creativa) transtextual e transcultural, por un pensamiento re-codificador de la historia (que descentra la historia), por un pensamiento heterogéneo o híbrido, subjetivo, de radical particularidad y de radical diversidad. La postcolonialidad no es excluyente, sino que incluye la multidimensionalidad, es decir, la interacción de diversas series codificadas del conocimiento con la finalidad de desenmascarar aquello que en el colonialismo y neocolonialismo había sido instaurado como la historia, como la verdad irrefutable, presentándolo como algo contradictorio e irregular. A través de este procedimiento se pueden interpretar las contradicciones, la multiplicidad, las rupturas y la discontinuidad de la historia y de la cultura concretizada en los diversos discursos, como por ejemplo en los discursos ficcionales. La postcolonialidad en su espíritu postmoderno inicia y funda, no polariza ni tampoco es militante. La militancia de los viejos discursos localistasnacionalistas es lo que en muchas épocas de la historia de la cultura han producido exactamente lo contrario: con su dogmatismo han impedido una discusión abierta y con ello el fomento y el desarrollo del OTRO en los centros culturales. Si no fuera por estos centros culturales, la periferia seguiría siendo periferia, periferizándose narcísticamente. 


\section{ALGUNOS CONCEPTOS FUNDAMENTALES}

\section{1 'Transculturalidad', 'Transtextualidad', 'Transdisciplinaridad'}

El cuestionamiento del Logos occidental y su inherente dualismo como así también las categorías 'Origen' y 'Verdad' en su sentido absoluto, significan la finalización de los discursos metanormativos, produciendo profundas consecuencias para los estudios culturales y sociales. Este cuestionamiento desarrolla un diálogo postcolonial desde donde se producen reformulaciones, recodificaciones y reinvenciones del propio contexto cultural en diálogo con las culturas hegemónicas, llevándose a cabo en tres áreas o estrategias: la 'transdisciplinaridad', la 'transtextualidad' y la 'transculturalidad' . Estos términos con el prefijo 'trans' representan una ampliación y deslimitación de aquellos con el prefijo 'inter' ya que se ubican en un supranivel epistemológico (vid. más abajo).

Bajo 'transdisciplinaridad' entendemos el recurso a modelos de diversas proveniencias disciplinaria y teórica (teatral, histórica, antropológica, sociológica, filosófica, estructural, postestructural, teoría de la comunicación, etc.) o a unidades o elementos particulares de éstos al servicio de la apropiación, decodificación e interpretación del objeto analizado. El término de transdisciplinaridad tiene poco que ver con aquel tradicional de la comparatística e interdisciplinaridad ya que allí los métodos de la propia disciplina de base no son transcendidos.

Bajo 'transculturalidad' se puede entender el recurso a modelos, a fragmentos o a bienes culturales que no son generados ni en el propio contexto cultural (cultura local o de base) ni por una propia identidad cultural, sino que provienen de culturas externas y corresponden a otra identidad y lengua, construyendo así un campo de acción heterogénea. Para la descripción de un semejante proceso se presenta el prefijo 'trans' - a raíz de su carácter global y nómada y por la superación del binarismo que este término implica- como más adecuado que el de 'inter', tan empleado en las ciencias teatrales desde comienzos de los 90. Especialmente en el teatro la circulación de distintos códigos culturales es de tal diversidad y conoce una enorme rizomatización que no se puede tratar en forma dialéctica, como más adelante lo demostraremos al discutir el concepto de la hibridez ${ }^{6}$.

Este proceso está estrechamente relacionado con la 'transtextualidad' en cuanto se trata del diálogo o de la recodificación de subsistemas y campos particulares de diversas culturas y áreas del conocimiento, sin que en este proceso se comience preguntando por el origen, por la autenticidad o la compatibilidad del empleo de unidades

5 El término 'transtextualidad' es empleado ya por Genette (1982: 7ss.) en la extensión aquí utilizada por nosotros. También Balme (1995: 7) habla de "comunicación transcultural". Una importante contribución, de la cual tomamos nota cuando este trabajo ya estaba terminado, es la de Welsch (1997a) y la de los trabajos de ese volumen misceláneo en su totalidad.

6 Desistimos del empleo del término 'Multiculturalidad' ya que está cargado de diversas implicaciones negativas, tanto políticas como ideológicas. 
culturales provenientes de otros sistemas. Simplemente su aspecto estético, su función social (y no su prefiguración) y su productividad representan el punto central de atención. Algo semejante es válido para el empleo de disciplinas científicas "auxiliares", que no son parte de la especialización. Se trata de un concepto de ciencia como diálogo, como punto de cruce o de entrelazamiento, como resultado de un parcours que está solamente al servicio del enriquecimiento de la interpretación.

El prefijo 'trans' no implica una actividad que diluya u obscurezca las diferencias culturales para luego conducirlas a un principio de producción sin rostro, dominado por un tipo determinado de mecanismos de la globalización. Sin embargo, también a través de la globalización se desafía la manifestación de la diferencia y alteridad (vid. más abajo). El prefijo 'trans' no se refiere a una nivelación de la cultura ni favorece el consumo, sino que se entiende como un diálogo desjerarquizado, abierto y nómada que hace confluir diversas identidades y culturas en una interacción dinámica (vid. también Kraniauskas 1992: 143-145).

\section{2 'Translación' ('Traducción'), 'Transformación' y 'Función'}

Estos tres términos incluyen complejos procesos sociales, culturales, pragmáticos, semánticos y mediales. Preferimos el término 'translación' al de 'traducción' ya que éste último implica especialmente aspectos lingüísticos, semánticos y pragmáticos que en nuestro contexto también son de central importancia-, pero que abarcan sólo una parte de un proceso de translación. El término de translación tiene un mayor campo de aplicación, abarca también aquellos antropológicos, étnicos, culturales, filosóficos, históricos, mediales y gestuales.

Mientras que la translación se puede considerar como un acto global en cuyo transcurso diversas unidades culturales se mueven de un contexto ' $x$ ' a uno ' $y$ ', se trata en el caso de la 'transformación' de cambios concretos, por ejemplo, en el campo lingüístico, cultural o pragmático-semántico. Se refiere al paso de una lengua a otra, a la transformación de códigos y de la forma de representación de su localidad cultural, desde donde se piensa y habla. El paso de un texto o acto codificado a otro, del texto a la representación, del director al actor y del autor al público implica serias transformaciones en todo nivel ${ }^{7}$.

El fenómeno de la translación con sus conllevadas transformaciones y cambio de funciones abarca tanto la teoría como la práctica del teatro. Especialmente en el teatro, producto híbrido en un medio público y en contacto directo con el espectador, la interpretación de procesos de translación es de fundamental importancia, ya que la hibridez resulta de una constante relación con otros referentes. Como en la hibridez, que también abarca diversos medios tales como los antropológicos (el encuentro entre diversas culturas y sistemas), los estéticos (diversos recursos a géneros y formas de

7 Deslimitamos el término 'texto', ampliando su sentido a cualquier tipo de expresión semiótica, sea ésta escrita, oral, iconográfica, kinésica, performativa u otra. 
expresión), los transmediales (recurso a diversos tipos como proyecciones de video, diapositivas, inclusión de monitores de TV, danza, artes plásticas, etc.), los filosóficos (simulación, rizoma), se debe analizar el cómo, el porqué y el para qué del empleo de estos medios que son de gran importancia cuando no se reducen a meros efectos estéticos (esteticismo). Así, por ejemplo, en la obra de Pavlovsky es indispensable analizar las categorías de rizoma y simulación, sobre todo en su rearticulación, que constituyen uno de sus pilares y a los que él mismo se refiere en sus metatextos.

La pregunta de la translación bajo la perspectiva de la hibridez y de la transmedialidad implica también el aspecto de la recepción, es decir, de qué manera se inscribe en la translación una forma de mediación que apunta a un público y cultura determinados. El teatro, siendo un evento público, un lugar de mediaciones directas, es a su vez representación de sí mismo (autorreferencial) y de la cultura, y con ello -en forma aún más acentuada que otras manifestaciones culturales- un punto entrecruzado de procesos culturales. La totalidad del proceso de escenificación es un factor esencial de translación ya que aquí se determinan todos los constituyentes que se inscriben transmedialmente en la representación teatral. Dentro de la translación se deben abarcar, en nuestro contexto, problemas y aspectos que se encuentran relacionados con procesos de hibridización, con estrategias de altaridad, es decir, con la inclusión de materiales codificados culturalmente y provenientes de diversas mediaciones.

\subsection{Globalización, cultura y medios}

La globalización conlleva profundos trastornos y cambios para la cultura, la lengua, el conocimiento y el pensamiento. De particular interés es la investigación de las manifestaciones culturales de este enorme proceso de transformación, solamente comparable con la revolución industrial, pero que tienen consecuencias aún mucho más graves -y casi imperceptibles- tanto para la sociedad e individuos en particular como para la cultura. En particular están afectadas todas aquellas culturas a las cuales se les ha impuesto la globalización o que han sido avasalladas, como es el caso en muchas regiones de Latinoamérica. En todo caso, la globalización conlleva tendencias que fomentan y estimulan la diversidad y hacen de ésta un principio de la acción cultural.

Colonialismo y neocolonialismo han sido las primeras y primitivas formas de una expansión globalizante que transformó las lenguas y las culturas de las "periferias". La colonialización no ha sido solamente un acontecimiento político, económico y religioso, sino que trajo la destrucción de las culturas locales a las cuales se les robaron la base de su forma de producción, sus instituciones políticas, jurídicas y su sistema de educación. El menosprecio de las culturas locales y simultáneamente la alta valorización de las culturas normativas de las potencias colonizadoras produce un 
sentimiento de “amenaza" contra la propia identidad (cfr. Villegas 1988, 1997) ${ }^{8}$. Por una parte, la globalización ha continuado y acentuado este tipo de tendencias después de la fase de la decolonización. Por otra, contiene -al contrario del colonialismo y del neocolonialismo- otro componente: la posibilidad de inaugurar un diálogo sobre la base de un cierto equilibrio. Esta deslimitación que trae consigo una serie de transformaciones, recodificaciones y reformulaciones en lo lingüístico-cultural ofrece también nuevas posibilidades.

Mientras más se expanda la globalización, más pierde el centro su posición de “centro", y la conjunción entre globalización y localidad quiebra los ejes generales y locales produciendo al fin una ampliación de los "centros" (o de "localidades-centro"). El desarrollo de tecnologías transmediales no ha conducido a un establecimiento de las culturas y formas de producción hegemónicas, sino que ha abierto nuevas formas de representación, ya que la globalización paradójicamente implica y exige formas descentradas de producción. Aun cuando debemos partir del hecho que la economía y la ciencia exigen uniformidad y disciplina, el resultado de la globalización en el campo de la cultura es la diversidad. La globalización transforma al mundo en un espacio descentrado, nómada y altamente cosmopolita de donde parte la hibridez. En particular los nuevos medios de comunicación han convergido en un tipo de comunicación transnacional que supera cualquier esencialismo de tal forma que existen paralelamente la similitud y la diversidad, lo extraño y lo local.

El teatro latinoamericano, por ejemplo, es un campo privilegiado en la investigación actual ya que desde sus formas premodernas y sobre la base de su historia y diversidad étnica y social siempre ha estado expuesto a procesos de globalización y alteridad. En la era moderna y postmoderna se agrega la expansión e implosión de los medios de comunicación de tal forma que la hibridez llega a ser una categoría y estrategia central.

\section{2. 'HIBRIDIZACIÓN' Y 'MEDIALIDAD'}

\section{1 'Hibridización'}

Tan sólo la mención del término 'hibridez' y otros relacionados con éste ofrece las primeras dificultades para su empleo, ya que existen diferencias en cuanto a su intención, extensión, similitud y relación con términos vecinos. Además el término de hibridez proviene de diversas disciplinas y de diversos contextos de argumentación. Mas las diversas denotaciones tienen, a pesar de todo, una base epistemológica similar y apuntan a fenómenos similares. Para poder lograr una operacionalidad del

8 Juan Villegas es uno de los primeros (o quizás el pionero) en el contexto de la ciencia del teatro que abre el camino para reflexiones de tipo teórico-cultural y de orden histórico, analizando muy tempranamente el problema de la perspectiva hegemónica, del problema de la lectura y de los sistemas de descripción en el teatro y la cultura latinoamericana. Véase también Gestos (1991). 
término hibridez, éste debe ser unificado y definido en ciertos contextos. Cualquier investigación que parta del fenómeno de la hibridez y de actos transculturales de comunicación deberá, antes que nada, solucionar este problema de definición y deberá proponer una concepción epistemológica para evitar aplicaciones contradictorias.

Lo primero que constatamos es que hibridez significa un movimiento nómada de fenómenos culturales con respecto al 'Otro' y a la 'Otredad', es un movimiento recodificador e innovador entre lo 'local' y 'lo externo'. Entendida la hibridez de esta forma evita reducciones esencialistas, el determinar la diferencia y la alteridad en un nivel ontológico prefigurado y posibilita llevar estas dos categorías a una diferancia y una altaridad, con lo cual se pueden entender diversas formaciones discursivas como deconstrucción y recodificación de "metadiscursos" oficiales y normativos.

Un buen ejemplo para un primer acercamiento o una primera descripción de la hibridez con relación a la transmedialidad y diversas formas de representación lo encontramos en la portada del libro Culturas Híbridas de García Canclini. Se trata del montaje que junta una pintura de Luis Felipe Noé con una fotografía de Lourdes Grobet y muestra a personas en la playa en Tijuana, en la frontera entre México y EE.UU. La pintura está constituida por una tela de colores que se encuentra colgada en una especie de andamio o de ventanas de metal con cuatro entradas; la tela se desborda más allá de ese andamio, hacia el exterior, lugar en el que se crea un espacio virtual donde se ubica la fotografía. Hibridez se da aquí en diversos campos en diversos niveles: por una parte consiste en un entrelazamiento (no en una síntesis) de diversos códigos en el nivel del productor que transporta un tipo de cultura, una historia y constelación social. En el nivel del medio de comunicación se encuentran la pintura y la fotografía; en el nivel del objeto confluyen la pintura abstracta y la representación realista de individuos que se entretienen en la playa. Un objeto es unidimensional, el otro pluridimensional. La foto narra una historia de migración, de las orillas (así también de opresión, explotación, persecusión y discriminación); la pintura se desenvuelve en un espacio estético-virtual que permite incorporar rizomáticamente otras formas de representación/expresión. La narración en la foto representa icónicamente el nomadismo y la hibridez en la frontera/orilla, ya que la cerca de metal es la línea de demarcación que separa a México de EE.UU., y aquí se ha permeabilizado. Tanto la foto como la pintura constituyen un espacio virtual y de simulación donde se diluyen las oposiciones binarias. De allí que en Tijuana la identidad sea indefinible según parámetros unívocos o monocausales: ésta es descrita como "posmexica, prechucano, panlatino, transterrado, arteamericano [...]" ( cita de García Canclini ${ }^{2}$ 1995: 302). Semejantes operaciones son típicas para el teatro como medio de representación.

Haciendo un primer resumen de lo expuesto hasta ahora, podemos decir que la hibridez se puede sistematizar partiendo de tres niveles que denominamos 'epistemológico' (aquí la hibridez es una archicategoría donde se generan las operaciones de principio), 'cultural' (estrategia de la negociación de la Otredad, la mirada sobre el 
Otro) y 'transmedial' (el punto de conjunción del origen de la función, como así también el tipo de estructura de los medios de representación empleados) ${ }^{9}$.

\subsubsection{Hibridez como categoría epistemológica y cultural}

El término 'hibridez', que en la teoría de la cultura por lo general y en Latinoamérica en particular es empleado en forma equivalente al de 'heterogeneidad' (cfr. Balme 1995; Brunner 1986: 178, 180; A. de Toro 1999), reúne también los términos de 'différance' (castellano: 'diferancia') y 'Altarity' (castellano: 'altaridad'). Bajo 'diferancia' se puede entender, en el contexto del presente trabajo considerando además aspectos sincrónicos y diacrónicos, una aproximación a la Otredad de la razón y de la historia, es decir, a una lógica de la 'suplementariedad', del 'pliegue', 'repliegue' ('reploiement'), 'arruga' ('pli'), 'injerto' ('greffe'), el rodar de unidades culturales que no se dejan reducir ni a un origen cultural o étnico único; se trata de unidades que se resisten a ser asimiladas por estructuras superiores. La resultante proliferación discursiva (trace) no conduce a una concepción del Otro como diferencia/exclusión, sino a una negociación de la Otredad, a una estrategia de la diferancia. Ésta no constituye una contradicción dialéctica en el sentido de Hegel, sino marca el límite crítico de la idealización y de la superación ('Aufhebung'), reinscribe las contradicciones y no las homogeniza, no las sintetiza, ni las adapta. Este tipo de pensamiento, que 'perlabora' ('verwindet') el dualismo logocentrista del pensamiento occidental y que describe en especial nuestra condición actual, siendo fundamental para los procesos de transculturalidad y globalización, se encuentra en estado germinativo en algunos discursos premodernos y se desarrolla luego en el discurso moderno de Latinoamérica.

La diferancia se puede entender dentro de la semiótica de la cultura y en el nivel de la representación como 'categoría sémica', que proviene de un campo en el cual se establecen los principios de la descentración de un pensamiento antilogocentrista y antidualista (= nivel de los principios).

Definiendo diferancia como la deconstrucción de un logos metafísico de origen occidental, podemos entender el término de altaridad como una categoría operacional de la diferencia para la descripción de encuentros concretos y heterogéneos. Altaridad es una categoría operacional que proviene de la filosofía, pero marca el proceso de la negociación de la diferencia cultural. No se trata pues, insistimos, de una superación hacia un nivel más elevado ('Aufhebung') ni de asimilación. Bajo negociación podemos entender un acto de apertura de complejísima naturaleza y no libre de conflicto. Este movimiento implica reciprocidad. La alteridad se potencia en

9 Este aspecto se podría ampliar a la economía y política ya que en muchas regiones culturales (como en Latinoamérica) la hibridez se encuentra como principio de estructura. Roberto Schwarz describe, por ejemplo en Ao vencedor as batatas (1977: 13-25), cómo en el año 1824 los derechos humanos se incorporan en la constitución del Brasil, a pesar de que en ese momento seguía existiendo la esclavitud. Con respecto a la investigación de la hibridez, vid. entre otras tantas las publicaciones de Bronfen/Marius/Steffen (1997), Fludernik (1998), Thomsen (1994), Werbner (1997), Young (1995). 
los discursos premodernos y de la modernidad a raíz de violentos encuentros (descubrimiento, colonización, neocolonización) de diversos sistemas religiosos, políticos, sociales, étnicos y culturales. En este contexto se debe investigar si es que se trata de una acción de violencia lo que marca y reafirma la diferencia o si es que se desarrollan formas incipientes de altaridad.

La altaridad rinde cuentas como forma operativa a las discontinuidades y rupturas de la historia y de la cultura que supeditadas a un concepto teleológico, normativo y causal fueron subyugadas o dejadas fuera de consideración. Altaridad puede por esto ser definida además como un archisemema en cuanto pone a disposición estrategias discursivas para encuentros culturales y para la Otredad (= nivel de aplicación 1: negociación).

Hibridez puede ser finalmente entendida dentro de la semiótica de la cultura como un archilexema que relaciona y conecta elementos étnicos, sociales y culturales de la Otredad en un contexto político-cultural donde poder e instituciones juegan un papel fundamental (= nivel de aplicación 2: conducta práctica). La hibridez está constituida por la diferancia y la altaridad. La hibridez contiene además otro componente que es de tipo étnico-etnológico proveniente de un pensamiento no occidental, que está acuñado por un tipo diverso de racionalidad, realidad e historia. Con esto hibridez es un término englobalizador que incluye otras subformas del trato de la Otredad tales como 'mesticismo', que se refiere en primer lugar a una mezcla de étnias, o como el de 'sincretismo', que por lo general se refiere a mezclas religiosas, culturales, pero también étnicas y todo tipo de superposiciones.

Balme (1995: 1 passim) emplea el término 'sincretismo' partiendo de Colpe (1975), Berner (1982), Clifford (1988), Coplan (1985) y Hauptfleisch (1987). En estrecha relación con el término 'performance culture' y 'syncretic performance', éste acuña el de "teatro sincrético" ("synkretistisches Theater") entendido como teatro y estrategia de mezclas postcoloniales, como recodificaciones (Balme 1995: 4) y equivale a nuestra definición de hibridez. Clifford habla de un "inventive syncretisme" (ibíd.: 22) en el sentido de estrategias y procesos de recodificación, es decir, de formas de altaridad.

En todo caso, el término sincretismo es altamente cuestionado y en la teoría de la cultura latinoamericana goza en parte de un estatus peyorativo a raíz de su trayectoria de significación en los siglos XVI y XVII, particularmente en relación con su significado en el siglo XIX y en la primera mitad del siglo XX, en cuanto este término se conecta con la denotación de un "estado impuro", razón por la cual ya ha sido reemplazado hace mucho por los de hibridez y heterogeneidad (cfr. Brunner 1986: 163-193; 1988; García Canclini 1990/1992/²1995 y A. de Toro 1999). Bajo sincretismo se entendía una bastardía, una mezcla negativa que amenazaba a la propia identidad y que conduciría inevitablemente a su disolución. Hoy en día podemos entender el término sincretismo -a diferencia de los de hibridez y heterogeneidad (A. de Toro ibid: 37, 38, 55)- como una realidad, un hecho, una situación de ser, mas no una estrategia o una hibridez avant la lettre. El sincretismo es más bien una experiencia social, histórica y antropológica entendida como resultado de un hecho 
colonizador sui generis y por esto no una operación cultural intencionada. El sincretismo es una superposición voluntaria o involuntaria de diferentes culturas.

Balme (1995: 17ss.) considera el término de sincretismo -a diferencia de Clifford- no como una conditio humana, sino como una categoría operacional claramente ubicada en un contexto histórico y geográfico bien definido, diferenciándolo de conceptos tales como 'eclecticismo', hibridez, 'creolización' y 'fusión'.

Nos parece poco productivo, por no decir obsoleto, entrar en una discusión sobre lo apropiado de uno u otro término, el favorecer a uno y desarrollar toda una diatriba en contra de otros, por esto nos conformamos con las siguientes y breves observaciones. Los términos no son al fin entidades ontológicas, sino el resultado de una operación normativa-predicatorial, aun cuando siempre se definen en contextos históricopragmáticos y culturales determinados. De primordial importancia para su empleo es constatar si un determinado término se debe rechazar o emplear según su tradición o según nuevas exigencias de la disciplina. El estricto rechazo que Balme (ibíd.: 17) hace del término 'eclecticismo' por ser una "indiferenciada recolección y combinación de ideas" ("unterschiedsloses Sammeln und Kombinieren von Ideen") que "no dispone de ninguna tradición histórica de ideas y de ciencias" ("ïber keine ideenoder wissenschaftsgeschichtliche Tradition verfügend") y que "por esto no representa un término científico" ("daher kein wissenschaftlicher Begriff"), nos parece algo reductora. Aun cuando esta observación fuese epistemológicamente correcta, el eclecticismo como procedimiento está más que establecido en el arte a partir del Manierismo o más tardar desde el siglo XIX y ni hablar del siglo XX. Por otra parte, reservar el término de hibridez solamente para la biología o botánica, reducirlo sólo a "fenómenos de mezcla entre la cultura colonial e indígena" ("Mischphänomene zwischen der kolonialen und indigenen Kultur") o considerarlo como mera "metáfora" y como un fenómeno de "bastardización" y por esto descalificarlo, a pesar de estar establecido ya desde hace más de una década en la teoría de la cultura, particularmente de la teoría de la postcolonialidad de origen angloparlante, nos parece bastante arbitrario y además inútil, especialmente en el mundo del Commonwealth (donde se difunde la publicación de Balme) y de Latinoamérica.

Balme resume los términos de creolización e hibridez en uno, lo cual también nos parece una reducción ya que el término 'creolización' apunta generalmente a procesos lingüísticos o a tratados específicos de la lingüística; en cambio, el término hibridez señala una estrategia empleada para afrontar problemas más globales, donde uno de ellos constituye la creolización. Por el contrario, evitar el uso del término 'fusión' en el contexto de una discusión transdisciplinaria nos parece aceptable ya que éste implica la con-fusión de procesos de alteridad, es decir, la eliminación de las diferencias de las culturas implicadas en el acto transcultural, teniendo como consecuencia que éstas ya no puedan ser percibidas en el "producto final".

Sostener que "en los casos de hibridez y fusión se trata de préstamos de otros campos de la ciencia que no tienen ni en la ciencia de la cultura ni el arte ningún punto de contacto" (Balme 1995: 18) ${ }^{10}$, nos parece también problemático ya que

10 La cita original reza: 
descarta toda aquella literatura que funda la teoría de la cultura y emplea o describe el término de hibridez desde los años 70 (cfr. para la Commonwealth p.e. Ashcroft et alii 1989; Ashcroft 1995). La misma crítica a la que Balme somete estos términos se podría aplicar al concepto de sincretismo dentro de la ciencia literaria y dentro de un tipo de ciencia analítica; éste tenía (y creo que lo sigue teniendo) un significado peyorativo, se entendía como una grave desviación de la teoría de la ciencia analítica racionalista $^{11}$. Asimismo y precisamente dentro de la construcción teórica de la teoría de la cultura y de los estudios culturales la amplitud de los "préstamos" es indispensable y constitutivo de estas disciplinas abiertas que exigen una deslimitación de las disciplinas tradicionales ya que operan en diversos sectores y campos simultáneamente; además de que hoy en día se opera partiendo de un concepto de ciencia transdisciplinario. En nuestro contexto argumentativo es importante recalcar que Balme, tanto en el contexto de las teorías postcoloniales como en el de la ciencia teatral que recurre a esas teorías, prácticamente no difiere -en su concepción respecto del término sincretismo- de lo que nosotros entendemos bajo hibridez.

Para terminar con este aspecto queremos indicar que términos científicos tanto en la ciencia literaria como del teatro (igualmente en la filosofía) siempre han sido y son metafóricos y se han tomado prestado de otros contextos científicos en los que tenían otra aplicación. Gran parte del aparato terminológico del estructuralismo literario y de la semiótica proviene, por ejemplo, de las matemáticas, de la lingüística, de las ciencias de la comunicación, la cibernética, etc., e indiferentemente de la opinión que se tenga sobre estas disciplinas, sus conceptos promovieron grandes y duraderos resultados en las humanidades.

El concepto o la estrategia de hibridez se puede resumir en el contexto de la teoría de la cultura postcolonial en Latinoamérica bajo los términos de rizoma y 'transversalidad', por ejemplo, cuando García Canclini habla del camino a seguir para poder describir hoy adecuadamente la cultura latinoamericana: "necesitamos ciencias sociales nómadas, capaces de circular por las escaleras que comuniquen horizontalmente los niveles"(1990/1992/21995: 15), o "adentro todo se mezcla, cada capítulo remite a los otros, y entonces ya no importa saber por qué acceso se llegó" (ibíd.: 16).

A saber, Deleuze/Guattari (1976) definen el rizoma basándose en seis principios que traducimos como mejor podemos: la 'conexión', la 'heterogeneidad', la 'multi-

Bei Hybridität und Fusion handelt es sich um Anleihen aus wissenschaftlichen

Anwendungsbereichen, die mit den Kultur- und Kunstwissenschaften keinerlei Berührung haben.

11 Un buen número de argumentos se puede también mencionar para la legitimación histórica y epistemológica del concepto de hibridez, de lo cual desistimos por su evidencia en la teoría postcolonial, al contrario del término sincretismo. La opinión de Balme (ibíd.: 32) que los conceptos hibridez y sincretismo no van más allá de algunas prerreflexiones, nos parece algo arbitraria, aún cuando coincidimos en que no existe una teoría general de la hibridez y de la alteridad, a pesar de que en los últimos años se han publicado numerosos trabajos al respecto que van más allá de meros prolegómenos. 
plicidad', la 'ruptura asignificante', la 'cartografía' y la 'decalcomanía'. Bajo los dos primeros entienden la proliferación del rizoma en todas las dimensiones de $\mathrm{n}-1$, el cambio de forma, su accidentalidad, la negación de la formación de árboles genealógicos, del dualismo y de la estructura profunda. No se trata de la codificación de diversos sistemas sígnicos, sino de fenómenos de diversa naturaleza: biológicos, económicos, políticos, culturales, etc. El tercer criterio lo definen como la multiplicidad, entendida como la falta de objeto y de sujeto; lo único posible para su aprehensión es la determinación, la cantidad y la dimensión. Simbólicamente hablando, el rizoma es una red, un tejido, donde solamente existen líneas y no se permite la supracodificación. Sus líneas son únicas y simples ya que ocupan su dimensión en forma total y no necesitan adiciones. Los autores dan un ejemplo del libro ideal: éste debería tener un plan donde en una hoja se reuniese la multiplicidad de elementos en su totalidad: experiencias, determinaciones históricas, concepciones, individuos, grupos $\mathrm{y}$ formaciones sociales. El rizoma descentra el lenguaje hacia otras dimensiones y registros para encontrarse a sí mismo. Este postulado se encuentra en estrecha relación con la concepción de la "paralogía" y del "debate" de Lyotard y con la de "simulación" de Baudrillard. Con el término de la "multiplicidad" se marca la determinación tradicional entre sujeto y objeto. Este cambio lo ilustran los autores en base a la marioneta:

Les fils de la marionnette, en tant que rhizome ou multiplicité, ne renvoient pas à la volonté supposée une d'un artiste ou d'un montreur, mais à la multiplicité des fibres nerveuses qui forment à leur tour une autre marionnette suivant d'autres dimensions connectées aux premières (Deleuze/Guattari ibíd.: 22).

El rizoma es, por lo tanto, una red donde solamente se encuentran líneas que se manifiestan en un encadenamiento siempre en mutación y en expansión. Deleuze y Guattari proponen, como ejemplo ideal, un libro con las siguientes características:

L'idéal d'un livre serait d'étaler toute chose sur un tel plan d'extériorité, sur une seule page, sur une même plage: événements vécus, déterminations historiques, concepts pensés, individus, groupe et formations sociales. (Deleuze/Guattari ibíd.: 25)

El cuarto principio describe la posibilidad de interrupción o destrucción de un rizoma, la imposibilidad del dualismo. El rizoma 'desterritorializa' un término incipiente de la cultura y lo 'reterritorializa' dentro del sistema rizomórfico. No existe ni la imitación ni la similitud, sino una explosión de dos o más series heterogéneas en líneas que son constituidas por un mismo rizoma y que no están subordinadas a un sistema superior. Por ejemplo: el cocodrilo no toma la forma de un tronco, como el camaleón no toma los colores de su medio ambiente y la "pantera rosa"no imita, no reproduce, sino que pinta el mundo con sus colores, "produce" rizomas, produce un mundo. Los criterios cinco y seis se refieren a la ausencia de un eje genético, de una estructura profunda, de una objetividad de unidades. El rizoma es una tarjeta con muchas entradas y no "copia de", está abierta a todas las dimensiones, es productiva y no una re- 
producción, es performancia y no competencia. Tenemos una evolución paralela de dos seres que nada tienen que ver el uno con el otro (Deleuze/Guattari ibíd.: 29). Un ejemplo de ello lo encontramos en Borges, en el cual esta constatación es central, puesto que no considera la literatura como un reflejo del mundo (Widerspiegelung), sino que ésta sostiene una relación rizomática con el mundo: la literatura crea un mundo, hace un mundo con el mundo. La literatura no es mimesis (un término que proviene del dualismo aristotélico), sino que crea otra realidad.

Como ya mencionamos, los principios 5 y 6 , los de la cartografía y decalcamonía, se refieren a la ausencia de un eje genético, es decir, a una estructura profunda o a un eje objetivo que se base en el principio de la copia única. El rizoma, por el contrario, no es copia sino mapa. Se trata de realizar mapas y no de realizar copias. Retomando el ejemplo dado anteriormente, "la orquídea no reproduce la copia de la avispa, ésta realiza un mapa con la avispa dentro de un rizoma" (Deleuze/Guattari ibíd.: 37). El mapa no reproduce, sino que crea. El rizoma es aquí un mapa con una multiplicidad de entradas y puede por esto conectarse en todas las direcciones, se puede variar, modificar, etc., está abierto para todo tipo de constelaciones, ya sea en un grupo o como categoría única. Mientras el mapa tiene que ver con la performancia, la copia está vinculada a la competencia:

Être rhizomorphe, c'est produir des tiges et filaments qui ont l'air de racines, ou mieux encore se connectent avec elles en pénétrent dans le tronc, quitte à les faire servor à de nouveaux usages étrages. (ibíd.: 46)

La práctica del rizoma significa "producir tallos y filamentos que se parecen a las raíces que, precisamente junto con éstas, penetran en el tronco para hacer un empleo inusual de las mismas" (Deleuze/Guattari ibíd.: 26).

Resumiendo, los elementos fundamentales del rizoma serían los siguientes: a) conexión arbitraria de puntos; b) producción de diversos sistemas sígnicos y de estados no-sígnicos; c) el rizoma no se puede reducir ni a uno ni a muchos otros; es indeterminable: no es un rizoma que se transforma en dos o viceversa; d) el rizoma no consiste en unidades, sino en dimensiones, es decir, no es una estructura, sino líneas; e) el rizoma desterritorializa y reterritorializa; f) el rizoma no es reproducción, sino producción; g) el rizoma no es copia, sino mapa.

El término de 'transversalidad' es creado por Welsch (1997) en su esfuerzo de desarrollar un nuevo concepto de racionalidad, donde transversalidad se puede describir como un tipo de pensamiento u operación de "cruces", de la "construcción de conecciones transversales entre diversos complejos" ("Erstellung querlaufender Verbindungen zwischen unterschiedlichen Komplexen", ibíd.: 761), como "diversas formas, intercambio y competencia, comunicación y corrección, reconocimiento y justicia" ("diverse Formen, Austausch und Konkurrenz, Kommunikation und Korrektur, Anerkennung und Gerechtigkeit", ibíd.: 762). Transversalidad "en un sentido genuino -no conoce "principios"” ("in einem eigentümlichen Sinne - >prinzipienlos`" ibíd.: 763), es decir, no existe una suma de principios prefigurados a priori. Se puede recurrir a diversas teorías sin tener por qué aplicarlas en su totalidad: 
La razón transversal no es un arche de algo establecido ni propiedad de principios establecidos, sino que es una razón siempre en movimiento, es realmente una capacidad operacional; en toda su forma es dinámica y se realiza en un proceso ${ }^{12}$.

El concepto transdisciplinario expuesto es, para el análisis del teatro, legítimo y adecuado por la simple razón de que el teatro latinoamericano no es otra cosa que una particular concretización de la cultura latinoamericana:

\begin{abstract}
Hoy concebimos a América Latina como una articulación más compleja de tradiciones y modernidades (diversas, desiguales), un continente heterogéneo formado por países donde, en cada uno, coexisten múltiples lógicas de desarrollo. Para repensar esta heterogeneidad es útil la reflexión [...] del posmodernismo, más radical que cualquier otra anterior. Su crítica a los relatos omnicomprensivos sobre la historia puede servir para detectar las pretensiones fundamentalistas del tradicionalismo, el etnicismo y el nacionalismo, para entender las derivaciones autoritarias del liberalismo y el socialismo. (García Canclini 1990/1992/21995: 23)
\end{abstract}

Hibridez es, pues, aquella estrategia o aquel proceso que tiene lugar en los puntoscruces o en los márgenes, en las orillas de una cultura, donde 'orilla'/'márgen' no implica siempre y fundamentalmente exclusión/discriminación, sino la articulación de nuevas formaciones culturales. Bajo 'puntos-cruces'/orillas/márgenes podemos entender de- y reterritorializaciones semiótico-culturales, en ellas se realizan las recodificaciones y reinvenciones. Se trata al menos de dos procesos: de la transposición de una unidad cultural de su lugar habitual en uno extraño, que debe ser nuevamente habitado, y de la mezcla de diversos medios de representación. Los medios masivos de comunicación han dejado atrás ya hace tiempo la ideología esencialista, de lo "puro-propio" como lo constatan reconocidos teóricos de la cultura latinoamericana, ${ }^{13}$ inaugurando un irreversible avance que también llega a las ciencias del teatro. Lo 'propio' de la cultura no se niega de manera alguna y está siempre presente, como lo demuestra la exportación mundial de telenovelas de Brasil, México y Venezuela. A pesar de todos los aspectos negativos que la acompañan, la globalización ha conducido en el campo de la cultura a un aumento de la producción cultural como constata Ortíz (1988: 182-206). La categoría de hibridez pone en relieve que la idea de una cultura "auténtica" y "coherente" ha sido siempre una ilusión en América del Norte y del Sur; igualmente se manifiesta esto hoy en día en Europa, resaltando que el recurrir a semejante "pureza conlleva el peligro de defender tendencias nacionalistas e ideologías conservadoras", como justamente anota Rosaldo (1989). La

12 Todas las traducciones al español son mías. El texto original de la anterior cita reza:

Transversale Vernunft ist nicht die Vernunft einer arche oder eines Bestandes oder Besitzes feststehender apriorischer Prinzipien. Sondern sie ist eine Vernunft der Bewegung, ist wirklich grundlegend ein Vermögen; sie ist ihrer ganzen Seinsart nach dynamisch, realisiert sich in Prozessen. (ibíd.: 764)

Vid. al respecto el panorama en mi trabajo, A. de Toro (1999). 
'identidad', lo 'auténtico' se negocia hoy en día en la diversidad de las orillas y en los puntos-cruces del encuentro de culturas (y no a través de oposiciones, sino por medio de operadores tales como "allí", "aquí", "en medio", "simultáneamente"): se vive simultáneamente en diversos mundos, en un "intermedio", en un espacio extraterritorial (Bhabha 1994; García Canclini 1990/ 1992/21995; A. de Toro 1999). La deterritorialización exige al mismo tiempo una reterritorialización que consiste en hacer habitable el "unhomely", el "in-between" (Bhabha 1994) a través de ofertas de posibles identidades. La fisura, la negociación cotidiana se transforma en el signo de identidad. Este doble movimiento trae consigo que diferencia y conflicto no desaparecen, sino que se encuentran en un espacio-inter-medio, aquel de la diferancia como una rodante suplementariedad para incorporarse en un contexto de la altaridad. De esta forma se puede conectar el nivel de la práctica discursiva-cultural con el nivel social.

\subsubsection{Hibridez y Teatro}

Comencemos con una pregunta: ¿Cómo pueden ser contectados los fenómenos de hibridez con aquellos del teatro, si no existe una teoría general de la inter- o transculturalidad? Creemos que esta teoría general no es necesaria y que además es imposible establecerla $^{14}$. Basta con recordar que tanto dentro como fuera de la discusión de la postmodernidad y de la postcolonialidad - y en este último caso en forma privilegiada a más tardar desde la publicación de las obras de Said, Ashcroft et alii, Todorov, Spivak, Bhabha o en el contexto de la teoría de la cultura desde la aparición de las obras de Brunner, García Canclini y Martín Barbero que se refieren a cruces, migraciones, Otredad, etc.--, contamos con una sólida basis para conectar ambos campos.

A más tardar desde la mitad de los años 80 en adelante constatamos en la ciencia teatral un creciente interés por los problemas de interculturalidad (cfr. bibliografía). Exactamente dentro del contexto de estas nuevas tendencias y recurriendo a una basta teoría de la cultura, particularmente a aquella sobre Latinoamérica, elaboramos nuestra propuesta. Una obra que ya había iniciado esta trayectoria con cierto mérito evidente es, por ejemplo, The Dramatic Touch of Difference, en donde se encuentran algunas iniciativas para la construcción de modelos y teorías sobre el tema a tratar, partiendo de concretizaciones escénicas específicas ${ }^{15}$.

14 No usamos el frecuente término de 'transferencia cultural' ('Kulturtransfer'), ya que éste se presta para malentendidos, en particular en el contexto de países postcoloniales, dentro de la crítica postcolonial, como es el caso en Latinoamérica en la era de la globalización. Bajo 'transferencia cultural' entendemos el 'exporte' hegemonial de productos del 'centro' a la 'periferia'. Por esto, el término de translación nos parece más adecuado.

15 Vid. también el libro Soziale und theatralische Konventionen als Problem der Dramenübersetzung (Fischer-Lichte/Paul/Schulze/Turk 1988), especialmente los trabajos de Turk y Fischer-Lichte que considero pioneros en este campo; vid. además Totzeva (1995); vid. también ahora último, Gestos $(1994,1996)$. 
El trabajo sobre hibridez exige al menos la consideración de los aspectos siguientes:

1. Para comenzar se debe partir de un modelo sobre la hibridez (nivel epistemológico) que ya desarrollamos brevemente más arriba.

2. Por parte de la producción deben ser descritas las unidades culturales que se encuentran en una obra teatral en el nivel de la referencia cultural (es decir, dentro de la propia cultura, por ejemplo en Brasil en relación con las culturas afroportuguesa, japonesa-brasileña) y fuera del espacio cultural propio. Se trata -como ya habíamos indicado- del entrelazamiento de diversos elementos que una cultura lleva consigo (nivel de la teoría de la cultura). En un segundo nivel, el de la obra de teatro misma, se investiga cómo estas unidades culturales constatadas se manifiestan en la semántica y pragmática del texto/escena, qué tipo de 'translaciones' y de 'transformaciones' han tenido lugar y cómo han sido éstas reinventadas/recodificadas. Este es el lugar de la investigación de la translación de las convenciones sociales en el medio del teatro. En este lugar se revela cómo el teatro transporta problemas sociales actuales o pasados y cómo se ha realizado esta translación (nivel de la representación).

3. Además se tienen que analizar al nivel del fluir de los entrelazamientos de los medios de representación, las concretizaciones de la sintáctica, del discurso, del actor (movimiento, desplazamiento, actos gestuales), de la voz, de la ideología y de la escenificación espectacular (escenografía/decorado, música, accesorios, etc.). El medio de representación del teatro (ya sea éste el texto de la representación o la representación misma) se encuentra en el centro del análisis, concentrándose en tres puntos fundamentales:

a) en la descripción, análisis e interpretación de la inscripción cultural (socialsociohistórica) de la hibridez en los niveles mencionados (de la translación de lo gestual, de la organización del movimiento y de la acción, de la lengua/palabra y de la imagen; el paso de un medio al otro es permeable);

b) en la descripción, análisis e interpretación del empleo de los diversos medios y formas de comunicación, tales como el empleo de tipos y subtipos de determinados textos (escenificación de artículos de prensa y noticias, de textos en verso y prosa, dramáticos y orales, etc. en el nivel de la transmedialidad);

c) en la descripción, análisis e interpretación de la relación de altaridad entre la cultura base (madre) y la externa;

4. En la descripción, análisis e interpretación de la recepción de formas teatrales híbridas; aunque se trate aquí un tipo arduo de investigación, ya que implica investigación de campo. 
La negociación de diferencias en el contexto de la hibridización no debe ser considerada como procedimiento de 'distanciación' ('Verfremdung') en el sentido que le dan los formalistas rusos a este término, ni tampoco como procedimiento de modelación secundaria en el sentido de Lotman, ya que estos autores no tratan la hibridez dentro de un concepto postcolonial (con la excepción de Lotman/Uspenskij 1978, 1984) que maneje estrategias de altaridad en el encuentro o confrontación de diversas culturas y recodificaciones. Recodificaciones, por su parte, no deben ser consideradas como meras apropiaciones o adaptaciones, un relicto de la exotización de culturas híbridas no occidentales que expone más bien un fenómeno de colonización. Se trata principalmente de un dar y recibir, de posibilidades de elección y selección, de formas de organización del espacio y del tiempo cultural, como así también de diversas formas de representabilidad.

El término teórico-cultural de hibridez contribuirá a aclarar preguntas referentes al tipo de formas teatrales, si se trata de meros préstamos de diversas culturas donde el diálogo en el momento del entrecruce carece de importancia y el interés radica simplemente en el préstamo (este sería el caso de un logo, euro y etnocentrismo, de un malinchismo típico en la modernidad, no así en una teoría de la cultura y del teatro de orientación postmoderna y postcolonial), o si se trata de reales estrategias de recodificación.

\subsection{Transmedialidad}

\subsubsection{Concepto y Problemas}

The hybrid or the meeting of two media is a moment of truth and revelation from which new form is born. For the parallel between two media holds us on the frontiers between forms that snap us out of the Narcissus-narcosis. Marshall McLuhan (1966: 55)

Modernidad y postmodernidad nos han brindado formas de comunicación cultural que hasta la fecha no habíamos experimentado en tal forma. La era de redes mediales de comunicación produce una multiplicidad de híbridos intermediales que se confrontan metamorfoseando con sus dinámicas y transformaciones mediales a significados textuales y sígnicos caducos. Jürgen E. Müller (1996: 15) ${ }^{16}$

16 El original reza:

Moderne und Postmoderne haben uns Formen kultureller Kommunikation beschert, wie wir sie bislang nicht kannten. Das Zeitalter medialer Vernetzungen produziert unzählige inter-mediale Hybride, die mit ihren medialen Dynamiken und Transformationen überkommene und fixierte Text- und Zeichenbedeutungen fortwährenden Metamorphosen in anderes aussetzen. 
Partiendo de los términos de transdisciplinaridad, transculturalidad y transtextualidad empleamos el concepto de 'transmedialidad', que no significa el intercambio de dos formas mediales distintas, sino una multiplicidad de posibilidades mediales. Además, este concepto incluye diversas formas de expresión y representaciones híbridas como el diálogo entre distintos medios -en un sentido reducido del término 'medios' (Video, Filme, TV)-, como así también el diálogo entre medios textuales-lingüísticos, teatrales, musicales y de danza, es decir, entre medios electrónicos, fílmicos y textuales, pero también entre no-textuales y no-lingüísticos como los gestuales, pictóricos, etc. Asimismo el prefijo 'trans' expresa clara y formalmente el carácter nomádico del proceso de intercambio medial ${ }^{17}$.

La transmedialidad se encuentra en estrecha relación con objetos culturales a raíz de la globalización que desde la modernidad a la postmodernidad ha incurrido en todos los campos de la vida de tal forma que ha afectado a la cultura, el arte y la ciencia; y, especialmente, se encuentran procesos mediales en el centro de cualquiera reflexión dentro de la teoría de la cultura. Este desarrollo no se refiere tan sólo a una sociedad siempre más condicionada por lo visual, que comienza en la modernidad como los pasajes y panoramas (cfr. Benjamin 1983, I/II), sino también a qué significados -en particular en la modernidad- obtienen un carácter primordialmente nómada y descentrado. Así, Lyotard (1973: 6) habla de los significados a la "deriva" o Deleuze (1988) de pliegues/arrugas (pli), que se concretizan en un desorden, hibridez o transmedialidad en las diversísimas formas de arte. En la transmedialidad se trata siempre de la transgresión de un límite, de 'pliegues', 'capas' y 'repliegues'.

La transmedialidad no es una mera agrupación de medios, esto no es un acto puramente medial-sincrético, ni tampoco es la superposición de formas de representación medial, sino -como en el caso de la hibridez- un proceso, una estrategia condicionada estéticamente y que no induce a una síntesis de elementos mediales, sino a un proceso disonante y con una alta tensión. Por esto gozan de central interés los campos de la transformación y funcionalidad de elementos mediales, ya que estos condicionan de forma decisiva la producción y recepción de productos culturales, su nivel pragmático y semántico. Elementos transmediales implican un proceder transcultural, transtextual y transdisciplinario ya que se alimentan de diversos sistemas y subsistemas.

Se puede hablar de transmedialidad siempre y cuando diversos elementos mediales concurran dentro de un concepto estético, cuando se constata un empleo multimedial de elementos y procedimientos o cuando éstos aparecen en forma de citas, es decir, cuando se realiza un diálogo de elementos mediales y se produce un metatexto-medial.

17 En la discusión actual se recurre con preferencia al término de 'intermedialidad', así HansenLöve (1983), Prümm (1987), Eicher (1994), Müller (1996), o al de 'multimedialidad', así Hess-Lüttich $(1982 ; 1984)$ y Prümm (1987). Con respecto a la transmedialidad en general y a la transmedialidad postmoderna, vid. Arens (1991), Auslander (1987), Bark (1990), Berringer (1991; 1991a), Hoesterey (1988) y Krämer (1998). 
La transmedialidad corresponde en el campo medial en parte al conocido fenómeno de la transtextualidad en cuanto que se establece un rico intercambio de formas mediales ${ }^{18}$. Por esto podemos definir este diálogo medial sin mayor problema con el término de 'textos mediales' (Müller 1996: 82), pero solamente si partimos de un amplio concepto de 'texto', según la semiótica de la cultura en el sentido que le da Derrida (1967) y que va más allá del reducido concepto de texto en la lingüística o de los términos de texto que se basan en ésta. El 'texto medial' no debe por esto entenderse como una expresión lingüística, sino simplemente como cualquier tipo de expresión que se hace en un contexto determinado (pinturas, tonos, música, ruidos, luz, cuerpo...).

Mientras el término transmedialidad acentúa el diálogo entre diversas expresiones mediales, esto es, principalmente entre diversos tipos de medios, artefactos, técnicas, el término de transtextualidad destaca el diálogo entre todas las posibilidades de expresiones textuales, sean éstas de naturaleza lingüística o no-lingüística. Mientras la transmedialidad subraya el tipo de artefacto, la transtextualidad resalta su contenido.

Lo descrito debe dejar suficientemente claro que el concepto de inter- o transmedialidad no debe confundirse con el de intertextualidad, ya que este último se refiere a textos lingüísticos que son solamente una variante de procesos de inter- o transmedialidad (cfr. también Büscher 1994: 193).

Finalmente, en el caso de la transmedialidad (como en el de la transtextualidad) se trata de un fenómeno transcultural y no nacional, ya que los procesos mediales tienen siempre efectos transnacionales y transculturales, desde el inicio de la Modernidad, por no decir a partir del Renacimiento.

\subsubsection{Transmedialidad y Teatro}

Como pocas publicaciones tematizan la relación teatro-medialidad y los campos relacionados a ésta, intentamos una breve descripción de esta relación. Los elementos mediales empleados en el teatro no son meramente formales, sino que determinan en forma decisiva el nivel semántico y pragmático de una obra, texto, representación y con esto el proceso de decodificación ${ }^{19}$. El teatro como forma medial de arte, comunicación y representación ha estado determinado de facto desde la antigüedad grecolatina, más especialmente de los años 60 por el empleo de diversos medios de representación (primero por la danza, la música y canto, luego por las artes plásticas y por composiciones de iluminación, por música electrónica estructurada por un

18 Con respecto a los pocos trabajos que tratan la relación teatro/intermedialidad, vid. HansenLöve (1983), Lehmann (1985), Zander (1985) y Müller (1996: 83; 93-103).

19 El trabajo de Müller (1996) es constructivo, sin embargo considera el teatro solamente al margen; vid. por el contrario Gestos (1994) y Villegas (2000) recién aparecido y que no alcanzamos incluir en este trabajo. 
ordenador, cfr. entre otros Finter 1994: 189ss.). El teatro en su totalidad, especialmente el postcolonial y el latinoamericano como punto entrecruzado por diversas culturas o formas culturales, se caracteriza por un empleo híbrido de elementos mediales.

La transmedialidad inherente al teatro (cfr. Hess-Lüttich 1984) se da al inicio en un campo elemental: primero el paso del texto dramático (escritura) a la representación (palabra, imagen, sonido, movimiento; cfr. F. de Toro 1987, 1995); luego del texto dramático al director (realización en tiempo y espacio, movimiento), al dramaturgo (reunión de materiales, reflexión sobre límites, posibilidades y excesos), al actor (cuerpo, voz) y finalmente al espectador (acto de recepción). Se suma, además, el traspaso de una unidad teatral de su contexto originario/base de su producción y representación a diversos medios de representación y reproducción (espacios teatrales y culturales). Este uso estético-funcional-híbrido que implica la transmedialidad es una parte constituyente en las obras de Alberto Kurapel (exiTlio in pectore extrañamiento; Mémoire 85/Olvido 86; Off-Off-Off ou Sur le Toit de Pablo Neruda; Prometeo Encadenado según Alberto Kurapel/Prométhée Enchainé selon Alberto Kurapel), de Gerald Thomas (Carmen com Filtro; Carmen com filtro 2; Mattogrosso; M.O.R.T.E; M.O.R.T.E. 2) o Robert Wilson (Cosmopolitan greetings; Parzival auf der anderen Seite des Sees; The Black Rider; The Casting of the Magic Bullets; Orlando), e igualmente en aquellas de Daniel Veronese y del grupo "Periférico de objetos" (Variaciones sobre B; El hombre de arena; Zooedipus), de Antunes Filho (Paraiso; Zona Norte; Nova Velha Estória) o en el teatro-danza de Johann Kresnik (Ulrike Meinhof) $^{20}$.

Una ciencia del teatro que esté interesada en analizar los elementos mediales no debe limitar el término 'medial' a la forma en la que se viene definiendo tradicionalmente como objeto de investigación dentro de las ciencias de la comunicación o lo que, hoy por hoy, se le atribuye al concepto de dialogicidad de Bajtín o al de intertextualidad en la ciencia literaria - como indicábamos más arriba-; el término se debe deslimitar en el sentido de diversas formas de comunicación cultural (exactamente en este aspecto radica el valor del trabajo de Müller 1996). Transmedialidad no se trata como un fin en sí mismo, sino como hibridez, es decir, como un instrumento al servicio de la descripción e interpretación del hecho teatral.

Transmedialidad no funciona solamente como una instancia productora de significación, sino que actúa al mismo tiempo como una instancia metatextual/representacional de la problematización del teatro y de la reflexión sobre el mismo, como artefacto, sobre sus posibilidades y límites. El empleo de diversos elementos mediales potencia (hace evidente) la autorreferencialidad teatral y acentúa la predominancia de formas de percepción sensorial, como por ejemplo lo visual y lo auditivo. La transmedialidad crea (o agrega) así otra denotación de teatralidad (vid. más abajo), ya

20 Con relación a la obra de Kurapel, vid. F. de Toro (1989; 1999; 1999a; 1999b) y A. de Toro (1991a; 1993; 1995); respecto de la obra de Gerald Thomas y Filho, vid. respectivamente Fernandes (1996) y Milaré (1994). 
que el teatro se define sobre la base de campos, materiales, objetos y procedimientos de gran diversidad, entre otros, imágenes, juegos y efectos de luces, proyecciones visuales, actores, cuerpo, biografías, autobiografías, pastiche, mezclas, etc. como en los ya mencionados Performances de Kurapel o en el teatro de objetos del grupo "Periférico de objetos". Estos elementos no están subordinados a la lengua, ni al actor o a una acción, sino que son actantes autónomos y constituyen un concepto de teatro que se deriva por una parte de formas tradicionales, y por otra de Performances, Events o recitativos (vid. más abajo).

\subsubsection{Transmedialidad e Hibridez}

También en la teoría de la cultura, particularmente en la latinoamericana, elementos mediales como video, televisión (telenovelas) y otras formas masivas de comunicación tienen un lugar de investigación privilegiado (cfr. Herlinghaus/Walter 1994 y A. de Toro 1999 con respecto a los trabajos de García Canclini, Martín Barbero, Ortiz, etc.), donde la estetización de la vida cotidiana, esto es, la confusión de los límites entre teatro como escenario y el espacio colectivo-público, la entrada de la calle al espacio teatral y el traspaso del teatro a la calle juegan un papel primordial; así en el "teatro de la memoria" de Alfredo Castro.

La conexión epistemológica entre hibridez y transmedialidad radica precisamente en esta deslimitación de las prácticas teatrales tradicionales que se derivan de la superación de discursos universales (géneros, tipos textuales, poéticas normativas) como resultado de un cambio radical de los conceptos de sujeto y realidad. Ambas estrategias tienen en común el encontrarse en un espacio "intermedio", en puntos entrecruzados en un espacio del "unhomely" o del "in-between", como Bhabha denomina los cruces antropológico-culturales. A una cultura híbrida le es inherente una medialidad híbrida. Lo que desde la perspectiva del "centro" se consideraba como una agresión contra la norma (vid. la posición de Voltaire respecto del teatro elisabetano y español de los siglos XVI y XVII que no siguiendo las normas poéticas neoaristotélicas califica como "teatro bárbaro", híbrido y bastardo al fin), y por esto inferior, pasa en la hibridez a ser un principio de estructura: el deambular, la peregrinación.

\section{3. 'TEATRO'/'TEATRALIDAD'/'TEXTO TEATRAL'}

El concepto de teatro que vamos a definir resulta primero de una reflexión teórica, teniendo en cuenta las bases epistemológicas relacionadas con los términos de hibridez y transmedialidad, segundo, se deriva del tipo de textos/representaciones teatrales elegidos y, tercero, de una aproximación teórico-cultural transdisciplinaria.

Constatamos que tan sólo el hecho de hablar de 'teatro' nos trae a la memoria un tipo de paradigma que está conectado con la idea de que el teatro es producción y 
recepción de una acción dispuesta en tiempo y espacio, realizada a través de un acto de comunicación lingüístico-mimético y altamente referencial. Este concepto de teatro, que proviene de Aristóteles y desde entonces acompaña a diversas poéticas normativas, le da a la lengua y al habla tal prioridad, que por siglos todos los otros elementos confluyentes fueron subordinados a un acto parlante. El teatro es, en este contexto, un acto de significación y portador de un mensaje. Además, autor y texto fueron también por mucho tiempo instancias exclusivamente determinantes que reglamentaban y regulaban las relaciónes texto dramático/texto espectacular, teoría e interpretación. El debate que promueve Koltès en los años 80 contra un teatro de directores o espectacular desprendido del autor en "protección" de la pureza de la puesta en escena de sus obras, demuestra la relevancia de este aspecto. Desde los años 60 en adelante experimentamos, paralelamente al teatro de autor/texto, la emancipación del director que cada vez más se transforma en un "creador" de las obras puestas en escena, pasa a ser el autor del texto espectacular. Aun cuando siga existiendo hoy en día un concepto canónico de teatro, y además cuantitativamante superior a las nuevas formas, el teatro experimenta una reclusión de la mimesis y referencialidad desde Jarry y Artaud, pasando por Ionesco y Beckett; una radical transformación que en la postmodernidad (desde fines de los años 50) se concretiza en formas como Happening, Living Theatre, Performance, en otras, que llevan a una total deslimitación de las normas - como indicabamos al comienzo del volumen. Teatro pasa a ser 'teatralidad', es decir, cualquier representación estético-artístico-lúdica que se realiza con el cuerpo (voz, gesto, movimiento) y a través de una basta serie de elementos jerárquicamente iguales que ponen en relieve su carácter ritual-artístico. Dentro de esta definición es secundario saber si los signos producidos son de naturaleza lingüística o no lingüística, si se emplean para la realización de una acción o para transportar un mensaje o no. También el lugar de la representación (la institución teatral, el espacio teatral tradicional) pierde su importancia al igual que la separación entre actor y personaje. Más bien parece que el actor "engulle" al personaje o que los personajes pasan a ser actores.

Montaje, collage, el juego simultáneo de diversas formas de representación como danza, maquillaje (máscara), medios electrónicos, mitos, tradiciones, fragmentación, etc. constituyen el término de 'teatralidad'. En este sentido nuestro concepto de teatralidad coincide en varios aspectos con aquel de Evreïnov a comienzos del siglo XX (citamos de Xander 1994: 113):

Bajo "teatralidad" como término entiendo una custodia estética de carácter abierto y tendencioso, que aún lejos de un recinto de teatro, sólo a través de un gesto cautivante, de una sola y bellamente expresada palabra produce proscenios y decoraciones, liberándonos fácil, alegre e irreversiblemente de las cadenas de la realidad. (Evreïnov 1912: 20$)^{21}$

21 El original reza:

Unter "Theatralität" als Terminus verstehe ich eine ästhetische Monstranz von offen tendenziösem Charakter, die, selbst weit von einem Theatergebäude 
En este concepto las categorías de espacio y tiempo pasan a segundo plano y el texto dramático ofrece tan sólo una variante de concretización teatral. El texto espectacular se convierte, con su enorme virtualidad, en la instancia determinante de la producción teatral, como queda claramente expuesto en Cosmopolitan Greetings (de Wilson/ Ginsberg/Gruntz/Liebermann), en Black Rider (de Wilson/Waits/Burroughs), en Orlando (de Wilson/Woolf), en Parzival auf der anderen Seite des Sees (de Wilson/ Dorst; cfr. A. de Toro 1995) o en textos de Pavlovsky, por ejemplo en La mueca, Potestad, Pablo y particularmente en Paso de Dos, las cuales resultan de una estrecha interacción entre texto, trabajo actorial y variaciones escénicas (vid. A. de Toro 1996: 72). El teatro se transforma en teatralidad: por una parte se convierte en una constructio autorreferencial, por otra, permite que se incluyan formas de representación que generalmente quedaban excluidas, tales como rituales, festejos de matrimonios, formas religiosas de expresión, etc. (cfr. Barba 1985; Schechner 1985, ${ }^{2} 1988$, 1990; Fiebach 1986, 1998; Balme 1995; Gissenwehrer 1994), que según principios genéricos se consideraban "impuras" y no artísticas. Asimismo, en el concepto de teatralidad se consideran aspectos antropológicos ${ }^{22}$. Igual que el concepto de texto y

entfernt, durch eine einzige bezaubernde Geste, durch ein einziges schön ausgesprochenes Wort Bühnenbretter und Dekorationen erzeugt und uns leicht, freudig und unabänderlich von den Fesseln der Wirklichkeit befreit. (Evreïnov 1912: 20)

22 Stefanek (1976: 219) postula la exclusión de representaciones rituales del concepto teatro. Esta postura, por lo demás bastante difundida, muestra la necesidad del concepto de teatralidad:

[...] eventos rituales pueden adquirir momentáneamente estructuras teatrales, pero no se les puede calificar de teatro por que les falta la distancia estética que separa la naturaleza diversa de actor y espectador, conectados en la convención de compartir una acción imaginaria.

([...] rituelle Veranstaltungen zwar momenthaft theatralische Strukturen enthalten, doch so lange nicht als Theater zu bezeichnen sind, als ihnen die ästhetische Distanz mangelt, aufgrund derer Darsteller und Zuschauer wesensmäßig voneinander getrennt, doch im Einverständnis der Partizipation an einer imaginären Handlung verbunden sind.)

Según esta definición, el teatro de Koltès tendría que ser excluido de la categoría teatro ya que rechaza la separación entre realidad/ficción ("odio el teatro", decía Koltès), de la misma forma se excluirían el Happening y el Performance. Al contrario de Stefanek, Victor Turner, Eugenio Barba y Richard Schechner (vid. bibliografía) nos ponen a disposición en su teoría y práctica teatral un concepto de teatro que incluye precisamente formas rituales de representación. Así, Schechner (1990: 49-112, en especial 68) considera en forma decidida que lo ritual es parte integral del teatro:

Por donde miremos en la actualidad y en el pasado siempre resulta ser el teatro un entrelazamiento de ritual y recreación. En un momento parece ser el origen el ritual, en otro es la recreación -gemelo acrobático- que juega sobrepuesto [...].

(Wo wir uns also umsehen und wie weit wir auch zurückblicken, immer stellt sich Theater als eine Verflechtung von Ritual und Unterhaltung dar. In einem Moment 
autor en el contexto de la semiótica y en la teoría textual (de la escritura) postmoderna de Derrida, Barthes, Lyotard y del Gruppe Tel Quel se transforma (hasta casi desaparecer), de la misma forma implica el concepto de teatralidad una profunda transformación, que radica en el carácter de proceso, de hibridez y de nomadismo en el teatro, incluyendo con esto elementos centrales de la discursividad postmoderna y postcolonial. 'Teatralidad' denomina también el momento de la representación independientemente de su forma de expresión, por lo tanto no se deja definir a través de un concepto de representación como se practicaba tradicionalmente en la semiótica teatral, que finalmente se basaba en un concepto lingüístico-estructural del signo (cfr. F. de Toro 1991; Balme 1995: 11-15) ${ }^{23}$.

El concepto de 'teatralidad' comprende también aquello que Goffman (1967, 1974a) llama la "social interaction", "performance" o teatro ritual (cfr. también Schechner 1985, ${ }^{2} 1988$, 1990; Turner 1982, 1987; Fiebach 1986, 1996, 1998). Barba constata que las formas de representación que no se ajustan al concepto tradicional de teatro no deben ser precisamente denominadas como "el otro teatro", sino se debe más bien hablar de "otras/diversas situaciones" que se comienzan a considerar como teatro. Con esto, Barba postula una deslimitación del concepto de teatro tradicional. Como el concepto 'teatro' - lo apuntábamos más arriba- está históricamente predeterminado por una fuerte tradición, el término de 'teatralidad' se ofrece, también por esta simple razón, como uno que es capaz de abarcar diversas situaciones teatrales que se escapan al paradigma (neo)aristotélico o (neo)realista.

El término de 'teatralidad' puede y debe ser un concepto que implica siempre una deslimitación y por esto no permite una definición. Más bien se determina a través de la descripción de los campos donde se aplica. El concepto puede entenderse como un lugar operativo en la construcción de relaciones transversales y entrelazamientos de diversas formas de representación, una operación transrelacional en el intercambio de comunicación, es decir, este concepto es a priori indeterminado, pero puede ser determinado en el sentido de una concretización histórico-cultural. Por consecuencia, aquello que se denomina como 'teatralidad' no posee una estructura tradicional, sino una 'estructura híbrida'. El término describe el empleo de una enorme e infinita posibilidad de procesos dinámicos de representación. La 'teatralidad' así descrita no puede entenderse como una categoría semántica (que se ocupa del contenido del acto de representación), sino como relación de diversas y simultáneas formas de representación.

scheint der Ursprung das Ritual zu sein, im nächsten Augenblick ist es die Unterhaltung - akrobatische Zwillinge, übereinander purzelnd, einer nie länger auf der Oberhand als der andere.) (ibíd.: 102)

23 La semiótica teatral de Pavis (1976, 1982), de Marinis (1982), Fischer-Lichte (1983) y F. de Toro (1988) se basa en la teoría general de la semiótica y pragmática adaptada al objeto teatro, sin embargo, estos autores describen y se aproximan al teatro en diversas formas y han tendido luego a desarrollar una "socio-semiótica teatral", una recepción teatral y últimamente concluyen en una teoría transcultural y postcolonial para el teatro (vid. bibliografía). 
Siguiendo a Evreïnov (en Xander 1994: 113-114), este concepto también se puede entender como una "ley general de la transformación creativa [...] del mundo percibido por nosotros" o como "instinto preestético" 24 , con lo cual Evreïnov deslimita el concepto de teatro hasta el punto que de facto lo elimina, como Xander (ibíd.: 114) apropiadamente indica. Semejante definición se asemeja, en el campo de las artes plásticas, a aquella de Beuys, quien fue famoso por su lema "cualquiera es un artista" y por declarar como arte cualquier instalación de desperdicios de la sociedad de consumo ('teatralidad'). Tanto el teatro como el arte en general pueden así "ser relacionados con cualquier tipo de representación de la vidad cotidiana". Esta concepción de Evreïnov fue visionaria - como también aquella con respecto a la importancia de los medios de comunicación de masa en el siglo XX- y es confirmada con la permanente teatralización de la vida cotidiana, por ejemplo en el campo de la política, donde como sabemos, ya no se trata de la representación de contenidos, de ideas o propuestas, sino de escenificaciones. De igual manera las "escenas" de la vida cotidiana (locales, comportamiento, vestimenta de "moda") consisten, como lo indica ya el término mismo, en autoescenificaciones ritualizadas que comienzan con la vestimenta y se concretizan en gestualidad y acción. En un punto diferimos de Evreïnov, Schramm (1990) y otros, en que el teatro "deba considerarse como el modelo para la comprensión de sistemas culturales" (Xander 1994: 115) ${ }^{26}$. El teatro es un sistema cultural entre otros que puede contribuir a comprender procesos culturales. Aun cuando podamos coincidir con Fiebach (1998: 7) que 'teatralidad' puede ser "definida como un encuentro cultural e histórico-cultural, socio-político y cotidiano", sería altamente arbitrario conceder al teatro un absoluto predominio en la producción cultural.

La deslimitación que el concepto de 'teatralidad' implica no debe conducirnos a la idea de que cualquier tipo de escenificación, por ejemplo las acciones cotidianas o políticas, sea una forma de 'teatralidad' ya que el término obtendría así una intención y extensión tan amplia que finalmente podríamos desistir de él. Por esto, 'teatralidad' puede ser definida tan sólo en relación con la categoría 'teatro' y con aquellas emparentadas con la misma. 'Teatralidad' sería luego una estrategia de producción metonímica y metafórica de situaciones similares al teatro. De lo metonímico/metafórico depende la frágil distinción entre teatralidad y otras formas que recurren a ella. Expuesto de otra manera: se trata del grado de autorreferencialidad, de la acción lúdica a la que apela el teatro para llevar a cabo una diferenciación, aunque reconocemos que en muchos casos los límites son permeables. Estamos aquí tratando un fenómeno similar al que se presenta cuando se quiere definir científicamente lo que

24 “[...] allgemeines Gesetz der schöpferischen Transformation [...] der von uns wahrgenommenen Welt" [...] "vorästhetischen Instinkt" [...] (en Xander ibíd.: 114).

25 “[...] auf beliebige Erscheinungen der Lebenswelt bezogen werden” (Xander ibíd.).

26 “[...] das Modell für das Verständnis kultureller Systeme überhaupt ansehen” (Xander ibíd.: 115). 
es o no es arte, lo que al fin es un acto arbitrario que depende mucho del momento y menos de los llamados valores universales.

A pesar de los problemas descritos, empleamos el término de 'teatralidad' porque no está determinado ni histórica ni normativamente, y así no excluye de partida formas que no se atengan al concepto tradicional de teatro. De igual forma operaban las poéticas y la investigación académica teatral cuando se trataba de definir y valorizar los géneros dramáticos ${ }^{27}$.

Como criterio de teatralidad y para un concepto híbrido de teatro importa en particular el carácter complementario del teatro, esto es, su producción o diseminación de la significación, que a pesar de su fuerte autorreferencialidad con el artefacto teatro no es idéntico con éste ni se agota en él, como sucede con los eventos de masa, con las corridas de toros, los campeonatos de fútbol o con los juegos olímpicos.

Además me parece importante la constatación de Xander (1994: 116) que Evreïnov "comprende la criminalidad como un fenómeno teatral y se ocupa en forma copiosa de preguntas sobre la sexualidad" 28 , lo cual corresponde al concepto de teatro de Pavlovsky (p.e. Cámara lenta, Potestad, Paso de Dos) o de Koltès (p.e. Combat de nègre et de chiens, Dans la solitude des champs de coton, Quai Ouest, Roberto Zucco).

En nuestros intentos por definir y describir el concepto de 'teatralidad' vemos, por una parte, que 'teatralidad' es el concepto que mejor abarca aquello que hoy llamamos teatro a nivel internacional y, por otra, en la discusión actual sobre una ciencia teatral transdisciplinaria y transcultural ${ }^{29}$.

Finalmente, no definimos el término 'texto teatral' en el sentido restrictivo de Balme (1995: 6) "[...] como la transcripción de la idea (imagen) de una puesta en escena", sino en un sentido abierto, como las diversas concretizaciones teatrales donde el predicado 'texto' -como ya lo habíamos indicado- abarca cualquier tipo de expresiones.

27 Cfr. Fiebach (1986: 9ss.), quien señala la imposibilidad de una exclusión normativa de formas de representación y la teatralización de la vida cotidiana. Compartimos la posición de Fiebach (ibíd.: 12) -entre tanto una opinión común en las ciencias del teatro y desde los años 30 en las artes plásticas- que "una diferenciación estricta entre 'teatro' y otras formas de comunicación, donde roles y autorrepresentación son fundamentales, no se justifica" ("[...] eine solche scharf ausschließende Unterscheidung zwischen 'Theater' und den Erscheinungen allgemeiner Kommunikation, in denen Rollenzeigen und Selbstdarstellungen wesentlich sind, nicht gerechtfertigt ist").

28 “[...] Kriminalität als ein theatralisches Phänomen versteht und sich ausführlich Fragen der menschlichen Sexualität [widmet]".

29 Por esto no coincidimos con Münz (1994: 29; 31) quien, basándose en los trabajos de Seige/Wolfram (1990, citados en Münz), resultados de la escuela de teatro de Leipzig, y al parecer en disputa con Fiebach, Kotte y Schramm, declara el concepto de 'teatralidad' como científicamente inaplicable. Sobre todo no alcanzamos a comprender lo que Münz (1994: 2829) quiere definir con el "concepto de teatro de Leipzig" y menos aún con aquel de "théaReihe". 


\section{4. 'CUERPO' - 'DESEO' - 'SEXUALIDAD' - 'PODER'}

\subsection{Cuerpo como categoría epistemológica-cultural-semiótica}

El estudio del 'cuerpo' como un campo o una categoría cultural, epistemológico/a, sexual, político/a y postcolonial ha sido poco trabajado/a en el ámbito latinoamericano (pero también en el hispánico) en comparación, por ejemplo, con estudios provenientes del contexto anglosajón o alemán; esta constatación es válida tanto para el campo del teatro como para el de la teoría de la cultura y deberá tener en el futuro una mayor atención. Sin embargo, también en el contexto norteamericanoeuropeo, a pesar de todo, encontramos déficits.

El cuerpo y sus partes constituyentes deben ser introducidos como rica materia de estudio para la interpretación, especialmente en el contexto teatral. El estudio del cuerpo en relación con la sexualidad, poder, pasión, violencia, perversión, lenguaje, memoria, historia, etc. es en el campo de la construcción teórica postmoderna y postcolonial de fundamental y central importancia. Esto significa devolverle al cuerpo su materialidad, su naturaleza que se le ha usurpado o prohibido expresar desde hace siglos, apoyándose en la oposición 'alma vs. cuerpo' (cuerpo como proyección del alma) y favoreciendo su "intelectualización", disciplinización, productividad y eficiencia (progreso) (vid. Kamper/Wulf 1982: 13ss.) e impecabilidad (culto de la belleza y eterna juventud corporal).

En nuestro contexto entendemos la categoría 'cuerpo' como una constructio híbrida y medial de las orillas, donde los límites entre victimarios y víctimas, entre poder e impotencia se permeabilizan y se confunden de tal forma que tienden a desaparecer (como ocurre en el teatro de Pavlovsky -en Potestad, Cámara lenta-, en el del grupo "Periférico de objetos" -Máquina Hamlet, Zooedipus- o en el de Koltès -por ejemplo en Roberto Zucco). En el contexto cuerpo se representan los temas de la represión, discriminación, opresión, confrontación, deseo y castigo, aquellos entre dispositivos de la sexualidad y del poder, entre un orden simbólico y uno imaginario.

Siguiendo a Foucault (1976: 121-123), entendemos bajo poder:

Par pouvoir, il me semble qu'il faut comprendre d'abord la multiplicité des rapports de force qui sont immanents au domaine où ils s'exercent, et sont constitutifs de leur organisation; le jeu qui par voie de luttes et d'affrontements incessants les transforme, les renforce, les inverse; les appuis que ces rapports de forces trouvent les uns dans les autore, de manière à former chaîne ou système, ou, au contraire, les décalages, les contradictions qui les isolent les uns des autres; les stratégies enfin dans lesquelles ils prennent effet, et dont le dessin général ou la cristallisation institutionnelle prennent corps dans les appareils étatiques, dans la formulation de la loi, dans les hégémonies sociales.

[...] le pouvoir [...] c'est le nom qu'on prête à une situation stratégique complexe dans une société donnée.

El poder, pues, no proviene solamente de arriba, de gobiernos, de instituciones, estados o de un simple binarismo que resulta de la relación dominador/dominado, sino 
también de abajo de las más pequeñas unidades sociales tales como la familia, el grupo de amistades, de colegas, y se desplaza a través de todas las instituciones hasta arriba. En el transcurso de este desplazamiento se reparten las relaciones de poder en forma nueva e incluso se invierten (vid. Foucault 1975: 35 passim), como lo experimentamos continuamente en las obras de Pavlovsky y Koltès. Poder es un proceso serial, nómada y rizomático, con esto altamente híbrido y ocupado por diversos medios de comunicación.

Estrechamente relacionado al dispositivo del poder, el cuerpo se encuentra en una relación negativa frente a aquellas de poder/sexualidad, norma/deseo y sus diversas circulaciones, máscaras y substitutos. El poder regula por ley el sistema binario de aceptación/prohibición del cual la sexualidad y el deseo tratan de subtraerse. La posibilidad de intervención del poder frente a la sexualidad y el deseo se expresa lingüísticamente en un discurso con carácter de ley, amenazando con censura y castigo.

De central interés, en el contexto del teatro, es el análisis e interpretación del cuerpo, de la norma y del deseo, de sus contradicciones, interrelaciones y dependencias sobre la base de dos estrategias sociales: poder y sexualidad, que como estrategias son -según Foucault- unidades dinámicas que recibimos y compartimos, perdemos o conservamos y que parten de una infinidad de lugares, deplazándose luego apoyadas en la multiplicidad de combinaciones. Con esto sexualidad es:

[...] grand réseau de surface où la stimulation des corps, l'intensification des plaisirs, l'incitation au discours, la formation des connaissances, le reforcement des contrôles et des résistances, s'enchaînent les uns avec les autres, selon quelques grandes stratégies de savoir et de pouvoir. (Foucault 1976: 139),y

Elle apparaît plutôt comme un pint de passage particulièrement dense pour les relations de pouvoir: entre hommes et femmes, entre jeunes et vieux [...] utilisable pour le plus grand nombre de manœuvres, et pouvant servir de point d'appui, de charnière aux stratégies les plus variées. (ibíd.: 136)

Para Foucault la sexualidad es:

[...] l'élément le plus spéculatif, le plus idéal, le plus intérieur aussi dans un dispositif de sexualité que le pouvoir organise dans ses prises sur les corps, leur matérialité, leurs forces, leurs énergies, leurs sensations, leurs plaisirs. (ibíd.: 205)

El dispositivo sexual lleva a los individuos al conocimiento de sí mismos, les pone en evidencia la totalidad de su cuerpo y de su identidad. Partiendo de esta base, entendemos el cuerpo per se por una parte como lenguaje (pero no en el sentido de "lenguaje del cuerpo" por medio del cual se desempeña el papel de un personaje, ni tampoco como transporte de significación dentro de un sistema lingüístico), y por otra como deseo, sin la finalidad determinada de reproducir un sistema lingüístico, sino con la intención de producir su propio lenguaje de donde se desprende el texto teatral: cuerpo como teatralidad. Así lo encontramos en trabajos de Wilson (Parzival auf der anderen Seite des Sees), de Pavlovsky (Paso de Dos) o de Kurapel (Prometeo Encadenado según Alberto Kurapel). El cuerpo funciona aquí como cifra, huella, 
historia y memoria, ya que la experiencia se inscribe en él. Con ello, el cuerpo es el punto de partida y el lugar de producción de significación y de diseminación. El cuerpo es percibido en su propia materialidad y es empleado como acción, como lenguaje y no como transportador "de algo extraño". Escribir/representar equivalen a cuerpo y viceversa, cuerpo es escritura/representación, acción.

Tanto el cuerpo como el poder deben ser entendidos como saber, como discursividad en cuanto siempre se trata de "la economía política del cuerpo", "[...] du corps et de ses forces, de leur utilité et de leur docilité, de leur répartition et de leur soumission" (Foucault 1975: 32), y en cuanto el poder mismo produce saber, es origen del saber, de allí que cuerpo y poder también se impliquen recíprocamente:

Il faut plutôt admettre que le pouvoir produit du savoir [...]; que pouvoir et savoir s'impliquent directement l'un l'autre. (ibíd.: 36)

Cuerpo, sexualidad, deseo y poder no se encuentran juntos en una superficie, sin embargo, todos ellos producen saber porque se presuponen y condicionan mutuamente. Cuerpo, sexualidad y deseo implican relaciones de poder y se producen dentro de semejantes relaciones (así Pavlovsky: Paso de Dos, Potestad, Cámara Lenta ...; Koltès: Dans la solitude des champs de coton, Quai Ouest, Combat de nègre et de chiens, Roberto Zucco).

\subsection{Cuerpo - Hibridez - Medialidad - Teatralidad}

El cuerpo ha sido entendido en el teatro por mucho tiempo como un signo icónico y como un portador de la lengua, acciones e ideologías, de tesis y de diversos mensajes. El cuerpo ha sido reducido a un signo lingüístico, explicado y empleado como un medio cognitivo. Estas reducciones han sido el resultado de la concepción de teatro como mimesis y como reproducción de la realidad. Se partía de un concepto unificado, monocausal y cerrado de la realidad y del sujeto, donde la relación entre signo y cuerpo y de ambos con los objetos y con la realidad se fundaba sobre la base de relaciones de equivalencia y de convención ${ }^{30}$. Este concepto se inscribió en un sujeto con una estructura coherente, marcadamente cognitiva, racional y lógico-causal, un sujeto con un discurso ético. Así, a pesar de la autonomía que Diderot (1751) le atribuye al gesto kinésico, el cuerpo permaneció un medio subalterno, ya que su valor era medido en relación con la producción de signos lingüísticos. Cuerpo y gestos representaban una duplicación de lo dicho en la tradición aristotélica, ilusionista o realista; y de facto, hasta Brecht, funcionó como paradigma (vid. A. de Toro 1993; 1995), aun cuando la valorización del cuerpo hubiera cambiado radicalmente con las teorías de Stanislavskij o Meyerhold a comienzos del siglo XX o con aquellas de Artaud en los años 30. Como resultado de la concepción de las reglas de bienséance,

30 Para el trato del cuerpo como material y como un sistema autónomo, la equivalencia y la convención son secundarias, ya que el cuerpo, en ambos casos, es reducido a signos lingüísticos. 
el cuerpo no gozó de autonomía; éste -como así también los "afectos"- fue considerado, en el contexto de una antropología occidental y cristiana determinada por la oposición 'cuerpo vs. alma', como irracional e inferior.

El favorecimiento general de las vanguardias europeas, después de 1945, de un teatro realista y políticamente comprometido o de un teatro que tratara de restaurar el sujeto y los valores del pasado - a pesar de que ese pretendido mundo coherente y armonioso hubiera desaparecido a más tardar después de la primera Guerra Mundialcontribuyó pasajeramente a reprimir el cuerpo como un signo estético autónomo, como significante. El cuerpo y con éste el teatro son empleados como un medio para otro tipo de significaciones que no están relacionadas con su naturaleza. Cuerpo/gesto - como todos los otros elementos constituyentes del teatro, entre otros la lenguafueron subyugados al absolutismo de la mimesis. El teatro era un medio literario y reflejo de un mensaje para la representación pública en un estrado. El cuerpo fue instrumentalizado, para fines ajenos a él, en la cultura (Kamper/Wulf 1982) y en el teatro. Faltaba el reconocimiento de la teatralidad 'en sí', del teatro como materialidad y con ello del cuerpo 'en sí' como un elemento central del teatro, como se daba ya en el último tercio del siglo XIX en la pintura, la música y la danza (p.e. en la poesía de los surrealistas o en el teatro de los dadaístas).

El cuerpo como categoría teórico-cultural en un contexto postcolonial constituye la marca para la materialidad, para representaciones mediales de la historia del colonialismo (memoria, inscripción, registro), de la opresión, tortura, manipulación, agresión y confrontación (transformación) de diversas culturas. La primera forma de encuentro es la mirada. Hábitos, características externas como color de la piel, formas gestuales, olor y vestimenta funcionan como lugar de conflicto que debe ser negociado, es a la vez el lugar de la fascinación y del terror como se da en Combat de nègre et de chiens, La nuit juste avant les forêts de Koltès, en Cámara lenta, Último Match de Pavlovsky o en Prometeo Encadenado según Alberto Kurapel. El cuerpo comienza a actuar a más tardar donde la lengua como medio de comunicación fracasa. El cuerpo queda como último refugio de la identidad. El cuerpo es el lugar de concreción de la memoria, deseo, sexualidad y poder. Las huellas en el cuerpo son de naturaleza múltiple y hablan por sí mismas, conllevan la opresión, la colonización y la decolonización.

El cuerpo no solamente está relacionado con la hibridez en el caso de diversas etnias, sino a razón de su naturaleza y de sus implicaciones, contiene y produce saber, dispositivos de poder, deseo y muerte, amor y odio, renuncia y entrega, aceptación y rechazo. El cuerpo representa en sí, con su materialidad, su historia y su conocimiento un medio autónomo; él es su propio medio de comunicación y no "función en relación con una tercera instancia". En el teatro antropológico de Barba, Brook o Schechner, pero también en el postmoderno de Wilson y Pavlovsky, el cuerpo es punto de partida para la espectacularidad (y no puesta en escena de/para/sobre), él es teatralidad, movimiento, melodía en sí. De esta forma el cuerpo pasa a ser, a través de Happenings y Performances, en el teatro ritual y/o antropológico cada vez más, y en forma más absoluta, material y mensaje al mismo 
tiempo. El medio 'cuerpo' es su propio mensaje; medio y mensaje constituyen una unidad, no máscara de/para algo, sino simplemente cuerpo.

La materialidad del cuerpo y su conocimiento lo convierten en objeto privilegiado de representación, esto es, de la teatralidad. En este contexto, Barthes (1973: 104-105) habla de "l'écriture à haute voix", de una "écriture vocale", que no es "parole", es decir, fonológica, sino fonética. La voz del cuerpo, de la corporali$\mathrm{dad} /$ voz-melodía no persigue la finalidad de transportar mensajes o emociones ajenos a él, sino que produce "incidents pulsionnels"; dicho de otra forma: se trata de efectos de situación de intensidad -como Pavlovsky acostumbra formular ("teatro/situaciones de intensidad"). El cuerpo es como "le langage tapissé de peau", como "la volupté des voyelles"/"stéréophonie de la chaire profonde”, según Barthes (ibíd.). En esta "écriture à haute voix" se trata de la manifestación del cuerpo y no de la construcción de sentido o lenguaje. Se trata de manifestación, juego, materialidad, sensualidad, aliento y carne de la voz/del cuerpo: "déporter le signifié très loin et à jeter, pour ainsi dire, le corps anonyme de l'acteur dans mon oreille: ça granule, ça grésille, ça rape, ça copue, ça jouit" (ibíd.).

El cuerpo se representa. El hecho de escribir está pensado para un público y siempre supone una especie de striptease, lo cual es válido para el teatro en forma doble. No solamente el texto dramático, sino que también el texto espectacular personifican a través de los actantes un nutrido desnudismo: del autor dramático, del director, de los actores frente al público que toma la función de un voyeurista. De ahí que el concepto sea equivalente al de teatralidad. Sin embargo, con el término cuerpo no designamos solamente el aspecto físico humano, sino también objetos -como en las obras del grupo "Periférico de objetos" (Máquina Hamlet, Variaciones sobre B, El hombre de arena, Zooedipus) - que se transforman en cuerpo de actor y que constituyen la teatralidad. Lo objeto-teatral se puede entender también como cuerpo, porque de igual forma origina saber, deseo, poder y violencia.

La aceptación del cuerpo como genuina teatralidad, es decir, no su realización lingüístico-semántica, sino su construcción en una variadísimo significante, corresponde con un repliegue de la lengua, con una despragmatización y desemantización del acto de comunicación lingüístico propiamente. Esto lo constatamos en una buena cantidad de obras, así en aquellas de Koltès (Combat de nègre et de chiens), de Wilson/Dorst (Parzival auf der anderen Seite des Sees), de Pavlovsky (Potestad) y en las del grupo "Periférico de objetos" (Veronese), donde fragmentos lingüísticos, ruidos, música e iluminación son los actores reales de la representación. Mientras que en las obras de Pavlovsky el cuerpo es como un signo de la experiencia comentado verbalmente, en las de Wilson es éste, en primer lugar, movimiento, formaciones, líneas, conquista/habitación del espacio y de tal manera se calcula hasta el último detalle. Las secuencias son acompañadas por gestualidad, música estridente, disonante, ruidos, gritos que reemplazan cualquier mimestismo o evitan el peligro de éste. Además, mímica, acrobacia y movimientos en cámara lenta o movimientos "robóticos" caracterizan las construcciones espacio-corporales en las obras de Wilson como lo indicamos más arriba. Wilson deja al cuerpo ser cuerpo en cuanto hace desa- 
parecer la diferencia entre cuerpo, actor y rol (asimismo Koltès, cuando dice "odio el teatro"); en palabras de Wilson:

[...] yo pensaba que él no podía mentir. Un actor habría intentado interpretar el papel, lo cual es siempre una forma de mentira. Mi teatro no interpreta. [...] Yo no creo que Chris trate de interpretar el papel de Perceval. Él es Chris y se encuentra en una situación determinada, de allí que sea Perceval y Chris a la vez. (Wilson en: Ehler 1990: 190ss.) ${ }^{31}$

En las obras del grupo "Periférico de objetos" los objetos se apoderan del espacio, lo invaden, y convierten al actor en su instrumento. También aquí, los más mínimos movimientos, conmociones de un dedo o de la boca, de una ceja son determinados casi matemáticamente. De esta forma tanto cuerpo como objetos se refieren a sí mismos, tematizan su materialidad y la del teatro. Estos movimientos, objetos y fragmentos lingüísticos/fónicos existen tan solo en el movimiento de su realización y pierden así su carácter tradicional, incluso el metafórico y metonímico.

En un tipo de teatro semejante se trata menos (o en lo absoluto) de la representación de un sujeto o realidad fragmentados como consecuencia de la deconstrucción del origen y de la verdad (no olvidemos aquí que tanto Wilson como Pavlovsky quieren representar $s u$ verdad), o como resultado de una sociedad de información digital y virtual (que a fin de cuentas también quieren comunicar y producir significación), sino más bien se trata del genuino interés del teatro de ser teatro como en el Living Theatre o en el ballet de John Cranco o John Neumeier (igualmente en el de Balanchine a comienzos del siglo XX). Danza es aquí en primer lugar movimiento, constelaciones de movimiento y experiencias de movimiento, construcción del espacio y no transportadora de construcciones semánticas o la narración de una historia (como en el ballet clásico). Pero en todo caso, el foco de interés de nuestra sociedad de información radica, sin duda alguna, en el ver, en el aspecto sensorial (y no cognitivo), como lo postula Susan Sontag $\left(1966 /{ }^{2} 1986\right)$, cuando dice que el arte postmoderno es un arte de los sentidos, donde la escritura, el libro, el teatro literario no tienen ya más un lugar.

El ya mencionado carácter híbrido del cuerpo y su tratamiento en la postmodernidad se descubre como un significante fragmentado, desemantizado y se convierte en punto "entrecruzado". En esta multiplicidad rizomática se inscribe un discurso postcolonial, en cuanto la cultura hegemonial - expresada en una concepción unitaria del cuerpo (y acompañada de significados prefigurados) - es superada. Cada mirada va, por una parte, a rellenar el significado-cuerpo de otra forma (como una posición cero semiótico-semántico-cultural); por otra, el cuerpo dejará (o no) conocer en una

31 El original reza:

[...] ich dachte, daß er nicht lügen könnte. Ein Schauspieler würde versuchen, die Rolle zu interpretieren, was immer eine Art Lüge ist. Mein Theater interpretiert nicht. [...] Ich glaube nicht, daß Chris versucht, die Rolle des Parzival zu interpretieren. Er ist Chris und er ist in einer bestimmten Situation, dadurch ist er Parzival und doch auch Chris. 
estructura profunda residuos de "lo propio". Se trata de descubrir e interpretar las imágenes (en las artes plásticas), en el movimiento (danza/teatro), en la escritura (literatura/drama, sistemas no-lingüísticos; cfr. Kamper/Wulf 1989 y Öhlschläger/ Wiens 1997).

Finalmente, en nuestro contexto son de central importancia la "performatividad", "la recurrencia productiva" del cuerpo y la resultante autor-escenificación como "copia sin original", donde el cuerpo no es esbozado a priori, sino en el transcurso de un proceso (cfr. Butler 1990, 1993). El cuerpo como materialidad y portador de saber que se inscribe o produce en éste es una permanente y cambiante constructio que se va edificando por medio de iteración, apropiación y/o rechazo sin terminar de construirse (Butler). A pesar de que Butler en su concepto psicoanalítico-antropológico no quiere entender el cuerpo ni como "autorrepresentación teatral" ni como "performan$c e$ ", existe, a pesar de todo, un puente entre cuerpo y teatralidad, como lo hemos venido demostrando hasta aquí. El cuerpo como materialidad se presenta como superficie de inscripción basándose en reiteraciones y, a través de diversas concretizaciones, se puede "leer". Por lo tanto, podemos entender el cuerpo como un "proscenio" teatral en el cual se inscriben y se leen procesos culturales, produciendo al mismo tiempo significación y diseminación. En la escritura, en los movimientos, en los gestos, en las máscaras, en la vestimenta y en los accesorios se inscriben residuos/ huellas del cuerpo.

Resumiendo: el "Retorno del Cuerpo" (Wiederkehr des Körpers, Kamper/Wulf) en el contexto de una ciencia teatral transdisciplinaria, particularmente en el teatro contemporáneo (y latinoamericano) como así también en aquel de siglos anteriores (en la época colonial), significa poner la categoría cuerpo en el centro de la investigación y derivar de allí estrategias de hibridización y altaridad, así como analizar desde él la repercusión de los medios de comunicación (cfr. Röttger 1997; Schade 1997; Müller 1997; Menke 1997; Balme 1997; Angerer 1997). 


\section{BIBLIOGRAFÍA}

\section{Obras}

Filho, Antunes. (1990). Paraíso, Zona Norte. Vídeo.

----. (1991). Nova Velha Estória. Vídeo.

Kurapel, Alberto. (1987). 3 Performances Teatrales. (exiTlio in pectore extrañamiento; Mémoire 85/Olvido 86; Off-Off-Off ou Sur le Toit de Pablo Neruda). Montréal: Humanitas.

----. (1989). Prometeo Encadenado según Alberto Kurapel/Prométhée Enchainé selon Alberto Kurapel. Montréal: Humanitas.

----. (1991). Carte de Ajuste ou Nous n'avons plus besoin de calendrier. Montréal: Humanitas.

----. (1995). La Bruta Interférence. Montréal: Humanitas.

Koltès, Bernard-Marie. (1984). La fuite à cheval très loin de la ville. Paris: Minuit.

----. (1985). Quai Ouest. Paris: Minuit.

----. (1986). Dans la solitude des champs de coton. Paris: Minuit.

----. (1988). La nuit juste avant les forêts. Paris: Minuit.

----. (1988a). Le retour au désert. Paris: Minuit.

----. (1990). Roberto Zucco. Suivi de Tabataba. Paris: Minuit.

----. (1993). Combat de nègre et de chiens. Paris: Minuit.

----. (1995). Sallinger. Paris: Minuit.

Kresnik, Johann. (1989). Ulrike Meinhof. Vídeo.

Pavlovsky, Eduardo. (1970/1970*). Último Match. (en trabajo conjunto con Juan Carlos Hermes). Buenos Aires: Ediciones Búsqueda.

----. (1976/1976*). Telarañas. Buenos Aires: Ediciones Búsqueda. También: (1980). Madrid: Editorial Fundamentos.

----. $\left({ }^{1} 1978 /{ }^{2} 1987 / 1981^{*}\right)$. Cámara lenta. Historia de una cara. Buenos Aires: Ediciones Búsqueda. También: (1989). Madrid: Editorial Fundamentos.

----. (1980/1971'). La mueca. Madrid: Editorial Fundamentos. También: (1988). Buenos Aires: Ediciones Búsqueda.

----. (1980/1973*). El señor Galíndez. Madrid: Editorial Fundamentos. También: (1986). Buenos Aires: Ediciones Búsqueda.

----. (1982/1983*). El señor Laforgue. Buenos Aires: Ediciones Búsqueda. También: (1989). Madrid: Editorial Fundamentos.

----. (1986/1987). Pablo. Buenos Aires: Ediciones Búsqueda. También: (1989). Madrid: Editorial Fundamentos.

* Indicamos con un asterisco la fecha de la primera puesta en escena de la obra respectiva. La otra fecha se refiere al año de publicación de la misma. 
---- (1987/1985*). Potestad. Buenos Aires: Ediciones Búsqueda. También: (1989). Madrid: Editorial Fundamentos.

----. (1988). Cerca. Buenos Aires: Ediciones Búsqueda.

----. $\left({ }^{1} 1989 / 21990 / 1990^{*}\right)$. Paso de Dos. Buenos Aires: Ediciones Búsqueda/Ayllu.

----. (1992). El Cardenal. Buenos Aires: Ediciones Búsqueda.

----. (1994/1994*). Rojos globos rojos. Buenos Aires: Ediciones Babilonia.

----. (1999/1998*). Poroto. Nueva versión para teatro. Buenos Aires: GalernaBúsqueda de Ayllu.

Thomas, Gerald. (1986). Carmen com Filtro. Vídeo.

----. (1988). Carmen com filtro 2. Vídeo.

---- (1989). Mattogrosso. Vídeo.

----. (1990). M.O.R.T.E. Vídeo.

---- (1991). M.O.R.T.E. 2. Vídeo.

Veronese, Daniel. (1991). Variaciones sobre B... (Grupo Periférico de Objetos). Vídeo.

---- /Emilio García Wehbi. (1993). El hombre de arena. (Grupo Periférico de Objetos). Vídeo.

---- /Heiner Müller. (1995). Máquina Hamlet. (Grupo Periférico de Objetos). Vídeo.

---- /Emilio García Wehbi. (1998). Zooedipus. (Grupo Periférico de Objetos). Vídeo. Wilson, Robert. (1987). Parzival auf der anderen Seite des Sees. Programa y Vídeo.

----. (1988). Cosmopolitan greetings. Programa.

----. (1990). The Black Rider. The Casting of the Magic Bullets. Programa y Vídeo.

----. (1991). Orlando. Programa y Vídeo.

\section{Crítica}

\subsection{Teatro y Performance}

Angerer, Marie-Luise. (1997). "Medienkörper/Körper-Medien: Erinnerungsspuren im Zeitalter der 'digitalen Evolution"”, en: Claudia Öhlschläger/ Birgit Wiens (edras.). Körper - Gedächtnis - Schrift. Der Körper als Medium kultureller Erinnerung. Berlin: Erich Schmidt. pp. 277-292.

Balme, Christopher B. (1995). Theater im postkolonialen Zeitalter. Studien zum Theatersynkretismus im englischsprachigen Raum. Tübingen: Niemeyer.

----. (1997). "'Re-membering the Actress': Zur Visualisierung von Geschlechterdifferenz in der englischen Schauspieltheorie des 18. Jahrhunderts", en: Claudia Öhlschläger/Birgit Wiens (edras.). Körper - Gedächtnis - Schrift. Der Körper als Medium kultureller Erinnerung. Berlin: Erich Schmidt. pp. 159-177.

Barba, Eugenio. (1985). Jenseits der schwimmenden Inseln. Reflexionen mit dem Odin-Theater. Theorie und Praxis des Freien Theaters. Reinbek: Rowohlt. 
Benamou, Michel/Charles Caramello (eds.). (1977). Performance in Postmodern Culture. Milwaukee: University of Wisconsin-Milwaukee.

Büscher, Barbara. (1994). "Theater und Elektronische Medien. Intermediale Praktiken in den siebziger und achtziger Jahren. Zeitgenössische Fragestellungen für die Theaterwissenschaft", en: E. Fischer-Lichte/W. Greisenegger/H. Lehmann (eds.). Arbeitsfelder der Theaterwissenschaft. Tübingen: Narr. pp. 193-210.

Coplan, David B. (1985). In Township Tonight: South Africa's Black City Music and Theatre. London: Longman.

De Marinis, Marco. (1982). Semiotica del teatro. Milano: Bompiani.

Diderot, Denis. (1751). "Lettres sur les sourds et les muets", en: ídem. Écrits Esthètiques. (En: Euvres). Versión alemana: (1968). Ästhetische Schriften. (Editado por Friedrich Basseng). 2 Volúmenes. Berlin: Aufbau.

Eco, Umberto. (1977). "Semiotics of Theatrical Performance", en: Drama Review, $21,1$.

Ehler, Ursula. (1990). Tankred Dorst, Parzival. Ein Szenarium. (Con una entrevista de Bob Wilson). Frankfurt a. M.: Suhrkamp.

Elam, Keir. (1980). The Semiotics of Theatre and Drama. London/Nework: Methuen.

Feiler, Max Christian. (1974). Die Logik des Theaters. München: Bruckmann.

Fernandes, Sílvia. (1996). Memória e invenção: Gerald Thomas em cena. São Paulo: Perspectiva.

Fiebach, Joachim. (1986). Die Toten als die Macht der Lebenden. Zur Theorie und Geschichte von Theater in Afrika. Berlin: Handelsverlag Kunst und Gesellschaft.

----. (1996) "Theatralitätsstudien unter kulturhistorisch-komparatistischen Aspekten", en: Wolfgang Mühl-Benninghaus (ed.). Spektakel der Moderne. Bausteine zu einer Kulturgeschichte der Medien und des darstellenden Verhaltens. Ber-liner Theaterwissenschaft. Vol. 2. Berlin: VISTAS Verlag. pp. 9-68.

----. (1998). Keine Hoffnung, keine Verzweiflung: Versuche um Theaterkunst und Theatralität. Berliner Theaterwissenschaft. Vol. 4. Berlin: VISTAS Verlag.

Finter, Helga. (1994). “Audiovision: Zur Dioptrik von Text, Bühne und Zuschauer”, en: Erika Fischer-Lichte/Wolfgang Greisenegger/Hans-Thies Lehmann (eds.). Arbeitsfelder der Theaterwissenschaft. Tübingen: Narr. pp. 183-192.

Fischer-Lichte, Erika. (1983). Semiotik des Theaters. Vol. 1-3. Tübingen: Narr.

----. (1990). The Dramatic Touch of Difference. Theatre, Own and Foreign. Tübingen: Narr.

----. (1992). "Die semiotische Differenz. Körper und Sprache auf dem Theater - Von der Avantgarde zur Postmoderne", en: Herta Schmidt/Jurij Striedter (eds.). Dramatische und theatralische Kommunikation. Beiträge zur Geschichte und Theorie des Dramas und Theaters im 20. Jahrhundert. Tübingen: Narr. pp. 123140. 
----. (1994). "Theatergeschichte und Wissenschaftsgeschichte: Eine bedenkenswerte Konstellation. Rede zur Eröffnung des Ersten Kongresses der Gesellschaft für Theaterwissenschaft e. V. in Leipzig", en: ídem/Wolfgang Greisenegger/HansThies Lehmann (eds.). Arbeitsfelder der Theaterwissenschaft. Tübingen: Narr. pp. 13-24.

----. (1995). "Theatricality: A Key Concept in Theatre and Cultural Studies", en: Theatre Research International, vol. 20, núm. 2: 85-89.

----. (1998). "Grenzgänge und Tauschhandel. Auf dem Wege zu einer performativen Kultur”, en: ídem (ed.). Theater seit den 60er Jahren: Grenzgänge der NeoAvantgarde. Tübingen/Basel: Francke. pp. 1-20.

----. (1998a). "Verwandlung als ästhetische Kategorie. Zur Entwicklung einer neuen Ästhetik der Performanz", en: ídem (ed.). Theater seit den 60er Jahren: Grenzgänge der Neo-Avantgarde. Tübingen/Basel: Francke. pp. 21-91.

---- /Christel Weiler/Klaus Schwind (eds.). (1985). Das Drama und seine Inszenierung. Tübingen: Niemeyer.

---- /Fritz Paul/Brigitte Schulze/Horst Turk (eds.). (1988). Soziale und theatralische Konventionen als Problem der Dramenübersetzung. Tübingen: Narr.

---- Josephine Riley/Michael Gissenwehrer. (1990). The Dramatic Touch of Difference. Theatre, Own and Foreign. Tübingen: Narr.

---- /Wolfgang Greisenegger/Hans-Thies Lehmann (eds.). (1994). Arbeitsfelder der Theaterwissenschaft. Tübingen: Narr.

Floeck, Wilfried. (1993). "Das moderne Theater Lateinamerikas im Blick der deutschen Forschung?", en: ídem/Karl Kohut (eds.). Das moderne Theater Lateinamerikas. Frankfurt a. M.: Vervuert. pp. 25-38.

Floeck, Wilfried/Karl Kohut (eds.). (1993). Das moderne Theater Lateinamerikas. Frankfurt a. M.: Vervuert.

Galante de Sousa, José. (1960). O teatro no Brasil. Subsídios para uma bibliografia do teatro no Brasil. Vol. I. Rio de Janeiro: Instituto Nacional do Livro.

----. (1960a). O teatro no Brasil. Evolução do teatro no Brasil. Vol. II. Rio de Janeiro: Instituto Nacional do Livro.

Girshausen, Theo. (1990). "Zur Geschichte des Fachs", en: Renate Mörmann. Theaterwissenschaft heute. Eine Einführung. Berlin: Reimer. pp. 21-40.

Gissenwehrer, Michael. (1994). "Die Theatralität des Gegenterrors. Ritual und theaterwissenschaftliche Forschung", en: Erika Fischer-Lichte/Wolfgang Greisenegger/Hans-Thies Lehmann (eds.). Arbeitsfelder der Theaterwissenschaft. Tübingen: Narr. pp. 60-74.

Goffman, Erving. (1967). Interaction Ritual. Essays on Face-to-Face Behavior. New York: Doubleday.

----. (1974). Les Rites d'interaction. Paris: Minuit. 
----. (1974a). Frame Analysis: An Essay on the Organisation of Experience. Cambridge: Harvard UP.

Helbo, André (ed.). (1975). Sémiologie de la représentation. Bruxelles: Complexe.

---- /J. Dines Johansen/Patrice Pavis/Anne Ubersfeld (eds.). (1987). Théâtre Modes d'approche. Bruxelles: Labor/Klincksieck.

Hauptfleisch, Temple. (1987). "Beyond Street Theatre and Festival: The Forms of South Africa", en: Maske und Kothurn, 33, 1/2: 175-188.

----. (1989). "Citytalk, Thetretalk: Dialect, Dialogue and Multilingual Theatre in South Africa", en: English in Africa, 16, 1, (may): 71-92.

Höfele, Andrea. (1991). "Drama und Theater: Einige Anmerkungen zur Geschichte und gegenwärtigen Diskussion eines umstrittenen Verhältnisses", en: Forum Modernes Theater, 6, 1: 3-23.

Kesteren, Aloysius van (ed.). Moderne Dramentheorie. Kronberg: Scriptor.

Kowzan, Tadeusz. (1975). Literature et spectacle. Paris: Mouton.

Lehmann, Hans-Thies. (1985). “Intertextualität als Problem der Inszenierung”, en: Christian W. Thomsen (ed.). Studien zur Ästhetik des Gegenwartstheaters. Heidelberg: Winter. pp. 33-45.

Menke, Bettine. (1997). "Körper-Bild und Zerfall, Staub. Über Heinrich von Kleists Penthesilea", en: Claudia Öhlschläger/Birgit Wiens (edras.). Körper Gedächtnis - Schrift. Der Körper als Medium kultureller Erinnerung. Berlin: Erich Schmidt. pp. 122-158.

Möhrmann, Renate (ed.). (1990). Theaterwissenschaft heute. Eine Einführung. Berlin: Reimer.

Milaré, Sabastião. (1994). Antunes Filho e a dimensão utópica. São Paulo: Perspectiva.

Müller, Jan-Dirk. (1997). "Das Gedächtnis des gemarterten Körpers im spätmittelalterlichen Passionsspiel", en: Claudia Öhlschläger/Birgit Wiens (edras.). Körper - Gedächtnis - Schrift. Der Körper als Medium kultureller Erinnerung. Berlin: Erich Schmidt. pp. 75-92.

Münz, Rudolf. (1994). “Das Leipziger Theatralitätskonzept als methodisches Prinzip der Historiographie älteren Theaters", en: Erika Fischer-Lichte/Wolfgang Greisenegger/Hans-Thies Lehmann (eds.). Arbeitsfelder der Theaterwissenschaft. Tübingen: Narr. pp. 25-4.

Pavis, Patrice. (1976). Problèmes de sémiologie théâtrale. Paris: Presse Université du Québec.

----. (1980). Dictionnaire du Théâtre. Paris: Sociales.

----. (1982). Voix et images de la scène. Essais de sémiologie théâtrale. Lille: PU de Lille.

----. (1983). Diccionario del teatro. (Traducción de Fernando de Toro). Barcelona: Paidos. 
----. (1987). "Le théâtre et les médias: spécifité et interférences", en: André Helbo (ed.). Théâtre, Modes d'approche. Bruxelles: Klincksieck. pp. 33-63.

----. (1990). Le théâtre au croisement des cultures. Paris: Corti.

----. (1996). "L'approche anthropologique et l'analyse interculturelle", dans: ídem. L'analyse des spectacles. Paris: Nathan. pp. 249-277.

----. (ed.). (sin fecha). Confluences. Paris: Bois Robert.

Pfister, Manfred. (1977). Das Drama. Theorie und Analyse. München: Fink.

Röttger, Kati. (1997). “Zerstückelte Körper: Die Materialisierung sprachloser Erinnerung auf der Bühne. Zur Historia de la Sangre der chilenischen Theatergruppe 'La Memoria'", en: Claudia Öhlschläger/Birgit Wiens (eds.). Körper - Gedächtnis - Schrift. Der Körper als Medium kultureller Erinnerung. Berlin: Erich Schmidt. pp. 38-56.

Schade, Sigrid. (1997). "Gedächtnis-Lücke-Kunst. Zu Vera Frenkels Inszenierung von Erinnerung in der Video-Installation From The Transit Bar", en: Claudia Öhlschläger/Birgit Wiens (edras.). Körper - Gedächtnis - Schrift. Der Körper als Medium kultureller Erinnerung. Berlin: Erich Schmidt. pp. 57-74.

Schechner, Richard. (1973/21994). Environmental Theater. An Expanded New Edition including "Six Axioms for Environmental Theater". New York/London: Applause.

----. (1982). The End of Humanism. Writing on Performance. New York: Performing Arts Journal Publications.

----. (1985). Between Theatre \& Anthropology. Philadelphia: UP of Pennsylvania.

----. (21988). Performance Theory. London/New York: Routledge.

----. (1990). Theateranthropologie. Spiel und Ritual im Kulturvergleich. Reinbek: Rowohlt.

---- Willa Appel (eds.). (1990/21993). By Means of Performance. Intercultural Studies of Theatre and Ritual. Cambridge: Cambridge UP.

Schmidt, Herta/Jurij Striedter (eds.). (1992). Dramatische und theatralische Kommunikation. Beiträge zur Geschichte und Theorie des Dramas und Theaters im 20. Jahrhundert. Tübingen: Narr.

Schramm, Helmar. (1990). "Theatralität und Öffentlichkeit. Vorstudien zur Begriffsgeschichte von 'Theater'", en: Weimarer Beiträge, 2: 223-239. Nuevamente en: (1990). Karlheinz Barck (ed.). Ästhetische Grundbegriffe. Studien zu einem historischen Wörterbuch. Berlin: Akademie Verlag. pp. 201-244.

----. (1993). "Theatralität und Schrift/Kultur. Überlegungen zur Paradoxie des Theaterbegriffes", en: TheaterZeitschrift, Heft 35: 101-108.

----. (1995). "The Surveying of Hell. On Theatricality and Styles of Thinking”, en: Theatre Research International, vol. 20, núm. 2: 114-118.

----. (1996). Karneval des Denkens. Theatralität im Spiegel philosophischer Texte des 16. und 17. Jahrhunderts. Berlin: Akademie Verlag. 
Stefanek, Paul. (1976). "Vom Ritual zum Theater: Zur Anthropologie und Emanzipation szenischen Handelns", en: Maske und Kothurn, 22, 3/4: 193-223.

----. (1992). Vom Ritual zum Theater: gesammelte Aufsätze und Rezensionen. Wien: Ed. Praesens.

Steinbeck, Dietrich. (1970). Einleitung in die Theorie und Systematik der Theaterwissenschaft. Berlin: de Gruyter.

Toro, Alfonso de. (1991). “Cambio de paradigma: el 'nuevo' teatro latinoamericano o la constitución de la postmodernidad espectacular", en: Iberoamericana, 43/44, 15, 2-3: 70-92.

----. (1991a). “Alberto Kurapel o el teatro plurimedial interespectacular postmoderno", en: Alberto Kurapel. Carta de Ajuste ou Nous n' avons plus besoin de calendrier. Montréal: Humanitas. pp. 7-24.

----. (1993). “Gli itinerari del teatro attuale: verso la plurimedialità postmoderna dello spettacolo o la fine del teatro mimetico-referenziale?", en: Massimo Canevacci/ídem (eds.). La communicazione teatrale. Un approccio transdisciplinare. Roma: Seam. pp. 53-110. Reimpreso en alemán: (1995). "Die Wege des zeitgenössischen Theaters: zu einem postmodernen Multimedia-Theater oder das Ende des mimetisch-referentiellen Theaters?", en: Forum Modernes Theater, Heft 2/10: 135-183.

----. (1996). "Das postmoderne Theater von Eduardo Pavlovsky", en: Maske \& Kothurn, 1: 67-92.

---- /Klaus Pörtl (eds.). (1996). Variaciones sobre el teatro latinoamericano. Tendencias y perspectivas. Frankfurt a. M./Madrid: Vervuert/Iberoamericana.

Toro, Fernando de. (1987). Semiótica del teatro. Del texto a la puesta en escena. Buenos Aires: Galerna/IITCTL. También en inglés: (1995). Theatre Semiotics. Text and staging in Modern Theatre. Frankfurt a. M.: Vervuert/Toronto: UP Toronto.

----. (1987a). "La práctica teatral del Odin Teatre y de la identidad actoral”, Manuscrito de International School of Theatre Anthropology, Salento. Reimpreso en: La Escena Latinoamericana, (1991), 6: 32-34.

----. (1988). "Toward a Socio-Semiotics of the Theatre", en: Semiotica, 72, 1-2: 3770.

----. (1989). "Prometeo Encadenado según Alberto Kurapel”, en: La Escena Latinoamericana, 1, (abril): 55-57.

----. (1990). (ed.). Semiótica y Teatro Latinoamericano. Buenos Aires: Galerna/ IITCTL.

----. (1991). "Hacia una nueva teatrología”, en: Espacio 5, 9: 21-30. También en: ídem. (1999a: 13-22).

----. (1993). "Post-Modern theatricality: Simulation, palimpsest, and rhizom", en: Gestos, año 8, 16, (noviembre): 23-50. También en: ídem. (1999a: 155-176). 
----. (1994). "Post-Modern Fiction and Theatricality: Simulation, deconstruction, and rhizomatic writing", en: Canadian Review of Comparative Literature, 21, 3, (september): 417- 443 .

----. (1999). "El Teatro de Alberto Kurapel o el Tercer Espacio Performativo", en: Alberto Kurapel. 10 Obras Inéditas. Teatro-Performance. Montréal: Humanitas. pp. 7-18.

----. (1999a). Intersecciones: Ensayos sobre teatro. Semiótica, antropología, teatro latinoamericano, post-modernidad, feminismo, post-colonialidad. Frankfurt a. M./Madrid: Vervuert/Iberoamericana.

----. (1999b). "Identidad, Alteridad y el tercer espacio: El teatro de Alberto Kurapel", en: ídem. Intersecciones: Ensayos sobre teatro. Semiótica, antropología, teatro latinoamericano, post-modernidad, feminismo, post-colonialidad. Frankfurt a. M./Madrid: Vervuert/Iberoamericana. pp. 218-229.

---- /Alfonso de Toro (eds.). (1993). Hacia una nueva crítica y un nuevo teatro latinoamericano. Frankfurt a. M./Madrid: Vervuert/Iberoamericana.

---- /Alfonso de Toro (eds.). (1998). Acercamientos al teatro actual. (1975-1995). Historia - Teoría - Práctica. Frankfurt a. M./Madrid: Vervuert/Iberoamericana.

Totzeva, Sophia. (1995). Das theatrale Potential des dramatischen Textes. Ein Beitrag zur Theorie von Drama und Dramenübersetzung. Tübingen: Narr.

Turner, Victor. (1982). From Ritual to Theatre: The Human Seriousness of Play. New York: Performing Arts Journal Publications.

----. (1987). The Anthropology of Performance. New York: Performing Arts Journal Publications.

----. (1989). Vom Ritual zum Theater. Der Ernst des menschlichen Spiels. Frankfurt/New York: Qumran/Campus.

Ubersfeld, Anne. (1977). Lire le théâtre. Paris: Éd. Sociales.

Unger, Thorsten/Brigitte Schultze/Horst Turk (eds.). (1995). Differente Lachkulturen? Fremde Komik und ihre Übersetzung. Tübingen: Narr.

Villegas, Juan. (1971). La interpretación de la obra dramática. Santiago: Ed. Universitaria.

----. (1982/21991). "Nueva" interpretación y análisis del texto dramático. Ottawa: Girol.

----. (1988). Ideología y discurso crítico sobre el teatro de España y América Latina. Minneapolis: Prisma.

----. (1997). Para un modelo de historia del teatro. Irvine: Gestos.

----. (1997a). "De la teatralidad y la historia de la cultura", en: Siglo XX/20th. Century. pp. 163-192.

----. (2000). Para la interpretación del teatro como construcción visual. Irvine (California): Ediciones de Gestos. 
Xander, Harald. (1994). "Theatralität im vorrevolutionären russischen Theater. Evreïnovs Entgrenzung des Theaterbegriffs", en: Erika Fischer-Lichte/Wolfgang Greisenegger/Hans-Thies Lehmann (eds.). Arbeitsfelder der Theaterwissenschaft. Tübingen: Narr. pp. 111-124.

\section{2 'Medialidad'/'Inter(trans)medialidad' y Teatro}

Arens, Katherine. (1991). "Robert Wilson: Is Postmodern Performance possible?", en: Theater Journal, 43, 1: 14-40.

Auslander, Philip. (1987). "Going with the Flow. Performance Art and Mass Culture", en: The Drama Review, 122: 119-136.

Bark, Karlheinz (ed.). (1990). Aisthesis. Wahrnehmung heute oder Perspektiven einer anderen Ästhetik. Leipzig: Reclam.

Berringer, Johannes. (1991). "Erschöpfter Raum - Verschwundene Körper”, en: Rötzer, Florian (ed.). Digitaler Schein. Ästhetik der elektronischen Medien. Frankfurt a. M.: Suhrkamp. pp. 491-518.

----. (1991a). "Video/Performance. A border Theory", en: Performing Arts Journal, 39: $54-84$.

Bohn, Reiner/Eggo Müller/Rainer Ruppert (eds.). (1988). Ansichten einer künftigen Medienwissenschaft. Berlin: Sigma.

Eicher, Thomas. (1994). "Was heißt hier Intermedialität?", en: ídem/Ulf Beckmann. (eds.). Intermedialität. Vom Bild zum Text. Bielefeld: Aisthesis. pp.11-28.

Großklaus, Götz. (1995). Medien-Zeit, Medien-Raum. Zum Wandel der raumzeitlichen Wahrnehmung in der Moderne. Frankfurt a. M.: Suhrkamp.

Hansen-Löve, Aage A. (1983). "Intermedialität und Intertextualität. Probleme der Korrelation von Wort- und Bildkunst - Am Beispiel der russischen Moderne", en: Wolf Schmid/Wolf-Dieter Stempel (eds.). Dialog der Texte. Hamburger Kolloquium zur Intertextualität. Wien: Institut für Slawistik der Universität Wien. pp. 291-360.

Hess-Lüttich, Ernst W. B. (ed.). (1982). Multimedial Communication. Semiotic Problems of its Notation. Tübingen: Narr.

----. (1984). "Multimediale Kommunikation als Realität des Theaters in theoriegeschichtlicher und systematischer Perspektive", en: Klaus Oehler (ed.). Zeichen und Realität. Akten des 3. semiologischen Kolloquiums Hamburg. Vol. III. Tübingen: Stauffenburg. pp. 915-927.

Hoesterey, Ingeborg. (1988). Verschlungene Schriftzeichen. Intertextualität von Literatur und Kunst in der Moderne/Postmoderne. Frankfurt a. M.: Athenäum.

Huffman, Kathy R./Dorine Mignot (eds.). (1987). The Arts for Television. Los Angeles: Museum for Contemporary Art.

Kamper, Dietmar. (1991). "Mimesis und Simulation. Von den Körpern zu den Maschinen”, en: Kunstforum, 114: 86-94. 
Krämer, Sybille. (1998). "Das Medium als Spur und Apparat", en: ídem (ed.). Medien, Computer, Realität. Frankfurt a. M.: Suhrkamp. pp. 73-94.

----. (1998a). "Sprache-Stimme-Schrift. Über Performativität als Medialität", en: Erika Fischer-Lichte/Doris Kolesch (eds.). Kulturen des Performativen. Sonderband Paragrana, Internationale Zeitschrift für Historische Anthropologie. Vol. 7. Heft 1. Berlin: Akademie Verlag. pp. 33-57.

Lyotard, Jean-François. (1985). Intermedialität und Postmoderne. Berlin: Merve.

McLuhan, Marshall. (1966). Understanding Media: The Extensions of Man. New York: McGraw-Hill.

Müller, Jürgen. (1996). Intermedialität. Formen moderner kultureller Kommunikation. Münster: Nodus Publikationen.

Prümm, Karl. (1987). "Multimedialität und Intermedialität", en: Theaterzeitschrift, IV, 22: 95-103.

Schneider, Irmela/Christian W.Thomsen (eds.). (1997). Hybridkultur: Medien, Netze, Künste. Köln: Wienand.

Zander, Horst. (1985). "Intertextualität und Medienwechsel”, en: Ulrich Broich/ Manfred Pfister (eds.). Intertextualität. Formen, Funktionen, anglistische Fallstudien. Tübingen: Niemeyer. pp. 178-196.

\subsection{Teoría de la Cultura}

Ashcroft, Bill. (1995). "Hybridity", en: ídem/Gareth Griffiths/Helen Tiffin (eds.). Post-Colonial Studies Reader. London/New York: Routledge. pp. 183-212.

Ashcroft, Bill/Gareth Griffiths/Helen Tiffin (eds.). (1989). The Empire Writes Back: Theory and Practice in Post-Colonial Literatures. London/New York: Routledge.

----. (eds.). (1995). Post-Colonial Studies Reader. London/New York: Routledge.

Berner, Ulrich. (1982). Untersuchungen zur Verwendung des Synkretismus-Begriffs. Wiesbaden: Harrassowitz.

Bhabha, Homi K. (1990). "Introduction: narrating the nation", en: ídem (ed.). Nation and Narration. London/New York: Routledge. pp. 1-7.

----. (1990a). "DissemiNation: time, narrative, and the margins of the modern nation", en: ídem. Nation and Narration. London/New York: Routledge. pp. 291-322.

----. (1994). The Location of Culture. London/New York: Routledge.

----. (1997). "Das Zwischen der Kultur”, en: Peter Weibel (ed.). Inklusion: Exklusion. Kunst im Zeitalter vom Postkolonialismus und globaler Migration. Köln: Dumont. pp. 68-73.

Bronfen, Elisabeth/Benjamin Marius/Therese Steffen (eds.). (1997). Hybride Kulturen. Beiträge zur Anglo-amerikanischen Multikulturalismusdebatte. Tübingen: Stauffenburg. 
Brunner, José Joaquín. (1986). "El proceso de modernización y la cultura", en: Gonzalo Martner (ed.). América Latina hacia el 2.000. Opciones y estrategias. Cáracas: Editorial Nueva Sociedad. pp. 163-193.

----. (1988). Un espejo trizado. Ensayos sobre cultura y políticas culturales. Santiago de Chile: Flacso.

----. (1994). Bienvenidos a la modernidad. Santiago de Chile: Planeta.

----. (sin fecha). Cartografías, de la modernidad. Santiago de Chile: Dolmen.

Clifford, James. (1988). The Predicament of Culture: Twentieth Century Ethnography, Literature, and Art. Cambridge (Mass.): Harvard UP.

Coelho Neto, José Teixeira. (1986). Moderno Pós-Moderno. São Paulo: Iluminuras.

Colpe, Carsten. (1975). "Die Vereinbarkeit historischer und struktureller Bestimmungen des Synkretismus", en: Albert Dietrich (ed.). Synkretismus im syrisch-persischen Kulturgebiet: Bericht über ein Symposium in Reinhausen bei Göttingen in der Zeit vom 4. bis 8. Oktober 1971. Göttingen: Vandenhoeck \& Ruprecht. pp. 15-37.

Dirlik, Arif. (1994). "The Postcolonial Aura: Third World Criticism in the Age of Global Capitalism”, en: Critical Inquiry, vol. 20, (winter): 328-356.

Fludernik, Monika (ed.). (1998). Hybridity and Postcolonialism. Tübingen: Stauffenburg.

García Canclini, Néstor (1982). Las culturas populares en el capitalismo. México: Nueva Imagen.

----. (1990/1992/21995). Culturas híbridas. Estratégias para entrar y salir de la modernidad. México/Buenos Aires: Sudamericana.

----. (1995a). Hybrid Cultures: Strategies for Entering and Leaving Modernity. (Traducción de Christopher L. Chiappari/Silvia L. López, prólogo de Renato Rosaldo). Minneapolis: Minnesota UP.

Herlinghaus, Hermann/Monika Walter (eds.). (1994). Posmodernidad en la periferia. Enfoques latinoamericanos de la nueva teoría cultural. Berlin: Langer.

Herlinghaus, Hermann/Utz Riese (eds.). (1997). Sprünge im Spiegel. Postkoloniale Aporien. Bonn: Bouvier.

Kessler, Michael/Jürgen Wertheimer (eds.). (1995). Multikulturalität. Tendenzen Probleme-Perspektiven. Tübingen: Stauffenburg.

Kraniauskas, John. (1992). "Hybridism and reterritorialization”, en: Travesía. Journal of Latinamerican Cultural Studies, 1: 143-146.

Martín-Barbero, Jesús. (1987/41997). De los medios a las mediaciones. Comunicación, cultura y hegemonía. México: Gili.

----. (1989). Procesos de comunicación y matrices de cultura. Itinerario para salir de la razón dualista. México: Gili. 
---- (1993). Communication, Culture, and Hegemony. From the Media to Mediations. (traducción de Elizabeth Fox/Robert A. White, introducción de Philip Schlesinger). London/Newbury Park/New Delhi: Sage.

Mignolo, Walter D. (1989). "Colonial Situation, Geographical Discourses and Territorial Representations: Toward a Diatopical Understanding of Colonial Semiosis", en: dispositio, vol. XIV, 36-38: 93-140.

----. (1989a). "Afterword: From Colonial Discourse to Colonial Semiosis", en: dispositio, vol. XIV, 36-38: 333-338.

----. (1993). "Colonial and Postcolonial Discourse: Cultural Critique or Academic Colonialism?”, en: Latin American Research Review, 28, 3: 120-134.

----. (1994). "Afterword: Writing and Recorded Knowledge in Colonial and Postcolonial Situation", en: Elisabeth Hill Boone/ídem (eds.). Writing without Words. Alternative Literacies in Mesoamerica \& the Andes. Duke: Duke UP. pp. 292313.

----. (1995). The Darker Side of the Renaissance. Literacy, Territoriality, \& Colonization. Ann Arbor: UP Michigan.

----. (1995a). “Occidentalización, imperialismo, globalización: herencias coloniales y teorías postcoloniales", en: Revista Iberoamericana. Número Especial dedicado a la Literatura Colonial: identidades y conquista en América, vol. LXI, 170171, (enero-junio): 27-40.

----. (1997). "La razón postcolonial: herencias coloniales y teorías postcoloniales", en: Alfonso de Toro (ed.). Postmodernidad y Postcolonialidad. Breves reflexiones sobre Latinoamérica. Frankfurt a. M./Madrid: Vervuert/Iberoamericana. pp. 51-70.

Ortíz, Renato. (1988). A Moderna tradição Brasileira. São Paulo: Brasiliense.

Raymond, Williams. (1958). Culture and Society. London: Chatto \& Windus.

----. (1961). The Long Revolution. London: Chatto \& Windus.

----. (1977). Marxism and Literature. Oxford: Oxford UP.

Rosaldo, Renato. (1989). Culture and Truth. The Remaking of Social Analysis. Boston: Beacon Press.

Said, Edward. (1979/21994). Orientalism. New York: Vintage Books.

----. (1983). The World, The Text and The Critic. Cambridge: Harvard UP.

----. (1993). Culture and Imperialism. London: Chatto \& Windus.

Scharlau, Birgit. (1989). (ed.). Bild - Wort - Schrift: Beiträge zur LateinamerikaSektion des Freiberger Romanistentages. Tübingen: Narr.

----. (ed.). (1991). Kulturelle Heterogenität in Lateinamerika: Bibliographie mit Kommentaren. Tübingen: Narr.

----. (ed.). (1994). Lateinamerika denken: Kulturtheoretische Grenzgänge zwischen Moderne und Postmoderne. Tübingen: Narr. 
Schwarz, Roberto. Ao vencedor as batatas: forma literária e processo social nos inícios do romance brasileiro. São Paulo: Livraria Duas Cidades.

Seed, Patricia. (1991). "Colonial and Postcolonial Discourse", en: Latin American Research Review, 26, 3: 181-200.

----. (1993). "More Colonial and Postcolonial Discourses", en: Latin American Research Review, 28, 3: 146-152.

Spivak, Gayatri Chakravorty. (1988). In Other Worlds. Essays in Cultural Politics. London/New York: Routledge.

----. (1990). The Post-Colonial Critic: Interviews, Strategies, Dialogues. (editado por Sarah Harasym). London/New York: Routledge.

----. (1993). Outside/Inside the Teaching Machine. London/New York: Routledge.

Taylor, Mark C. (1987). Altarity. Chicago: Routledge.

Thomsen, Christian W. (1994). Hybridkultur: Bildschirmmedien und Evolutionsformen der Künste. Annäherungen an ein interdisziplinäres Problem. Siegen: DFG Sonderforschungsbereich 240.

Todorov, Tzvetan. (1982). La conquête de l'Amérique. La question de l'autre. Paris: Seuil.

----. (1989). Nous et les autres. La réflexion française sur la diversité humaine. Paris: Seuil.

Toro, Alfonso de (ed.). (1997). Postmodernidad y postcolonialidad. Breves reflexiones sobre la cultura latinoamericana. Frankfurt a. M. /Madrid: Vervuert/Iberoamericana.

----. (1999). “Cambio de paradigma en el pensamiento latinoamericano. Postcolonialidad/postmodernidad y Latinoamérica - Discusión en el contexto de la teoría de la cultura latinoamericana bajo el signo de la globalización”, en: ídem/Fernando de Toro (eds.). El debate de la postcolonialidad en Latinoámerica. Una postmodernidad periférica o Cambio de paradigma en el pensamiento latinoamericano. Frankfurt a. M. /Madrid: Vervuert/Iberoamericana. pp. 31-77.

---- /Fernando de Toro (eds.). (1999). El debate de la postcolonialidad en Latinoamérica. Una postmodernidad periférica o Cambio de paradigma en el pensamiento latinoamericano. Frankfurt a. M. /Madrid: Vervuert/Iberoamericana.

Toro, Fernando de. (1999c). "The Post-Colonial Question: Alterity, Identity and the Other(s)", en: Alfonso de Toro/ídem (eds.). El debate de la postcolonialidad en Latinoamérica. Una postmodernidad periférica o Cambio de paradigma en el pensamiento latinoamericano. Frankfurt a. M. /Madrid: Vervuert/Iberoamericana. pp. 101-136.

----. (1999d). Exploration on Post-Theory: Toward a Third Space. Frankfurt a. M./ Madrid: Vervuert/Iberoamericana.

---- /Alfonso de Toro (eds.). (1995). Borders and Margins: Post-Colonialism and Post-Modernism. Frankfurt a. M. /Madrid: Vervuert/Iberoamericana. 
Vidal, Hernán. (1993). "The Concept of Colonial and Postcolonial Discourse: A Perspective from Literary Criticism”, en: Latin American Research Review, 28, 3: 113-119.

Werbner, Pnina (ed.). (1997). Debating Cultural Hybridity. Multi-Cultural Identities and the Politics of Anti-Racism. London: Zed Books.

Werlen, Iwar. (1984). Ritual und Sprache. Zum Verhältnis von Sprechen und Handeln in Ritualen. Tübingen: Narr.

Young, Robert J. C. (1995). Colonial Desire. Hybridity in Theory, Culture and Race. London/New York: Routledge.

\subsection{Crítica diversa}

Bachtin, M. Michail. (1979). Die Ästhetik des Wortes. (Editado e introducido por Rainer Grübel). Frankfurt a. M.: Suhrkamp.

Barthes, Roland. (1973). Le plaisir du texte. Paris: Seuil.

Baudrillard, Jean. (1981). Simulacres et simulation. Paris: Galilée.

Benjamin, Walter. (1983). Das Passagen-Werk. Vol. I./II. Frankfurt a. M.: Suhrkamp.

Breger, Claudia/Dorothea Fronhof/Dagmar von Hoff. (1999). "Gender Studies/Gender Trouble. Tendenzen und Perspektiven der deutschsprachigen Forschung", en: Zeitschrift für Germanistik, Neue Folge IX, 1: 72-113.

Butler, Judith. (1990). Gender Trouble. London/New York: Routledge.

----. (1993). Bodies That Matter. London/New York: Routledge.

Deleuze, Gilles. (1975). Kafka pour une littérature mineure. Paris: Minuit.

----. (1988). Le pli. Leibniz et le baroque. Paris: Minuit.

---- /Félix Guattari. (1976). Rhizome. Paris: Minuit.

Derrida, Jacques. (1967). De la grammatologie. Paris: Seuil.

Foucault, Michel. (1975). Surveiller et punir. Naissance de la prison. Paris: Gallimard.

----. (1976). Histoire de la sexualité 1. La volonté de savoir. Paris: Gallimard.

----. (1978). Dispositive der Macht. Michel Foucault über Sexualität und Wahrheit. Berlin: Merve.

Genette, Gérard. (1982). Palimpsestes. La littérature au second degré. Paris: Seuil.

Gestos. (1991). "Representations of the Otherness in Latinamerican and Chicano Theatre and Film", año 6, núm. 11, (abril).

Gestos. (1994). "Postmodernism and Cultural Criticism: Chicano, Latin American, Luso-Brazilian, Spanish, and U.S. Latino Theatre", año 9, núm. 17, (abril).

Gestos. (1996). "Theatricality as Multidisciplinary Strategy", año 11, núm. 21, (abril). 
Kamper, Dietmar/Christoph Wulf (eds.). (1982). Die Wiederkehr des Körpers. Frankfurt a. M.: Suhrkamp.

---- /Christoph Wulf (eds.). (1983). Das Schwinden der Sinne. Frankfurt a. M.: Suhrkamp.

---- /Christoph Wulf (eds.). (1989). Transfigurationen des Körpers. Spuren der Gewalt in der Geschichte. Berlin: Reimer.

Le Goff, Jacques. (1988). La nouvelle histoire. Bruxelles: Complèxe.

Lotman, Iuri/Boris A. Uspenskij. (1978). "On the semiotic Mechanism of Culture", en: New Literary History, 9, 2: 211-232.

----. (1984). The semiotics of Russian culture. (Editado por Ann Shukman). Ann Arbor: University of Michigan.

Lyotard, Jean-François. (1973). Dérive à partir de Marx et Freud. Paris: Union Générale d'Éditions.

----. (1982). Essays zu einer affirmativen Ästhetik. Berlin: Merve.

----. (1984). Ökonomie des Wunsches. Bremen: Impuls.

----. (1994). Le différend. Paris: Minuit.

Oehler, Klaus (ed.). (1984). Zeichen und Realität. Akten des 3. semiologischen Kolloquiums Hamburg. Vol. I-III. Tübingen: Stauffenburg. (Sobre todo: Vol. III: "Multimediale Kommunikation als Realität des Theaters").

Öhlschläger, Claudia/Birgit Wiens (eds.). (1997). Körper - Gedächtnis - Schrift. Der Körper als Medium kultureller Erinnerung. Berlin: Erich Schmidt.

Schade, Sigrid. (1997). "Körper und Macht. Theoretische Perspektiven bei Adorno und Foucault", en: Sigrid Weigel (edra.). Flaschenpost und Postkarte. Korrespondenzen zwischen Kritischer Theorie und Poststrukturalismus. Köln/Weimar/ Wien: Böhlau. pp. 117-126.

Sontag, Susan. (1966/21986). Against Interpretation. New York: Ferrar Straus Giroux.

Weigel, Sigrid. (1994). Bilder des kulturellen Gedächtnisses. Beiträge zur Gegenwartsliteratur. Dülmen-Hiddingsel: Tende.

Welsch, Wolfgang. (1997). Vernunft. Die zeitgenössische Vernunftkritik und das Konzept der transversalen Vernunft. Frankfurt a. M.: Suhrkamp.

----. (1997a). “Transkulturalität. Zur veränderten Verfassung heutiger Kulturen”, en: Irmela Schneider/Christian W. Thomsen (eds.). Hybridkultur: Medien, Netze, Künste. Köln: Wienand. pp. 67-90.

White, Hayden. (1973). Metahistory. The Historical Imagination in NineteenthCentury Europe. Baltimore/London: The Johns Hopkins UP.

----. (1978). Tropic of Discourse: Essays on Cultural Criticism, Baltimore/London: The Johns Hopkins UP.

----. (1987). The Content of the Form. Narrative Discourse and Historical Representation. Baltimore/London: The Johns Hopkins UP. 